\title{
Assessing Urban Accessibility in Monterrey, Mexico: A Transferable Approach to Evaluate Access to Main Destinations at the Metropolitan and Local Levels
}

\author{
Ana Luisa Gaxiola-Beltrán ${ }^{1}\left(\mathbb{D}\right.$, Jorge Narezo-Balzaretti ${ }^{1} \oplus$, Mauricio Adolfo Ramírez-Moreno ${ }^{1, *} * \mathbb{C}$, \\ Blas Luis Pérez-Henríquez ${ }^{2}$ (D) , Ricardo Ambrocio Ramírez-Mendoza ${ }^{1}$ (D), Daniel Krajzewicz ${ }^{3}$ (D) \\ and Jorge de-Jesús Lozoya-Santos ${ }^{1} \mathbb{D}$ \\ 1 Tecnologico de Monterrey, School of Engineering and Sciences, Eugenio Garza Sada 2501 Sur, \\ Monterrey 64849, Mexico; a01113679@itesm.mx (A.L.G.-B.); jnarezo7@gmail.com (J.N.-B.); \\ ricardo.ramirez@tec.mx (R.A.R.-M.); jorge.lozoya@tec.mx (J.d.-J.L.-S.) \\ 2 Mexico Clean Economy 2050, Stanford University, Stanford, CA 94305, USA; blph@stanford.edu \\ 3 German Aerospace Center, Institute of Transport Research, Rudower Chaussee 7, 12489 Berlin, Germany; \\ daniel.krajzewicz@dlr.de \\ * Correspondence: mauricio.ramirezm@tec.mx
}

check for updates

Citation: Gaxiola-Beltrán, A.L.;

Narezo-Balzaretti, J.;

Ramírez-Moreno, M.A.;

Pérez-Henríquez, B.L.;

Ramírez-Mendoza, R.A.; Krajzewicz,

D.; Lozoya-Santos, J.d.-J. Assessing

Urban Accessibility in Monterrey,

Mexico: A Transferable Approach to Evaluate Access to Main Destinations at the Metropolitan and Local Levels. Appl. Sci. 2021, 11, 7519. https:// doi.org/10.3390/app11167519

Academic Editor: Vicente Julian

Received: 30 June 2021

Accepted: 6 August 2021

Published: 17 August 2021

Publisher's Note: MDPI stays neutral with regard to jurisdictional claims in published maps and institutional affiliations.

Copyright: (c) 2021 by the authors. Licensee MDPI, Basel, Switzerland. This article is an open access article distributed under the terms and conditions of the Creative Commons Attribution (CC BY) license (https:/ / creativecommons.org/licenses/by/ $4.0 /)$.
Abstract: Cities demand urgent transformations in order to become more affordable, livable, sustainable, walkable and comfortable spaces. Hence, important changes have to be made in the way cities are understood, diagnosed and planned. The current paper puts urban accessibility into the centre of the public policy and planning agenda, as a transferable approach to transform cities into better living environments. To do so, a practical example of the City of Monterrey, Mexico, is presented at two planning scales: the metropolitan and local level. Both scales of analysis measure accessibility to main destinations using walking and cycling as the main transport modes. The results demonstrate that the levels of accessibility at the metropolitan level are divergent, depending on the desired destination, as well as on the planning processes (both formal and informal) from different areas of the city. At the local level, the Distrito Tec Area is diagnosed in terms of accessibility to assess to what extent it can be considered a part of a 15 minutes city. The results show that Distrito Tec lacks the desired parameters of accessibility to all destinations for being a 15 minutes city. Nevertheless, there is a considerable increase in accessibility levels when cycling is used as the main travelling mode. The current research project serves as an initial approach to understand the accessibility challenges of the city at different planning levels, by proving useful and disaggregated data. Finally, it concludes providing general recommendations to be considered in planning processes aimed to improve accessibility and sustainability.

Keywords: urban accessibility; Distrito Tec; Monterrey Metropolitan Zone (MMZ); Urban Basic Geostatistical Areas (AGEBs); 15 minutes city; UrMoAC

\section{Introduction}

Currently, planet Earth and all its inhabitants are living during the key moment to stop climate change. According to UN-Habitat [1], cities are responsible for more than $60 \%$ of the world's greenhouse emissions and are thus an important part of the problem. Nevertheless, the authors of the present paper believe that cities are also the solution, but only if immediate and effective actions are taken within them.

Urban planners and decision-makers have been exploring new ways to reconfigure and build cities, with the objective of making more livable, safe, affordable, environmentally friendly and sustainable urban realms. However, the rate of change is not fast enough to meet the needs to stop climate change. Certain cities are advancing faster than others; therefore, the current project has decided to analyse to what extent the City of Monterrey, 
Mexico, is transforming to become a more accessible environment for its inhabitants by using sustainable modes of transport to provide access to its main destinations.

Monterrey is one of the largest cities in Mexico, with an area of $324.8 \mathrm{~km}^{2}$ and 1,142,994 inhabitants according to the 2020 census of the National Statistics and Geography Institute (INEGI, by its acronym in Spanish). This city shares its urban environment and transportation infrastructure with eighteen municipalities, which comprise the Monterrey Metropolitan Zone (MMZ): Abasolo, Apodaca, Cadereyta Jiménez, El Carmen, Ciénega de Flores, García, San Pedro Garza García, General Escobedo, General Zuazua, Guadalupe, Juárez, Monterrey, Pesquería, Salinas Victoria, San Nicolás de los Garza, Hidalgo, Santa Catarina and Santiago. According to INEGI, the population of the MMZ is 5,341,177 inhabitants within a $7657 \mathrm{~km}^{2}$ area.

Even though Monterrey is one of the wealthiest cities in Mexico, due to its industrial workforce and productivity, it faces several environmental and urban mobility challenges [2]. Monterrey has been previously identified as the second-most-polluted city in Latin America and holds the ninth place amongst most polluted cities in the world [3]. This pollution problem is produced by carbon and co-pollutant emissions from both traffic and industry. The city's urban mobility statistics have shown an increasing trend in the number of vehicles, while the use of public transportation has been decreasing [2]. Public transportation in the MMZ lacks security, is expensive and is often described as timely inefficient, making private vehicles the preferred choice for inhabitants [3].

The weather in Monterrey can also affect the citizens' willingness to use certain modes of transportation, such as walking and bicycles. Temperatures in the MMZ can reach extremely high values surpassing $35{ }^{\circ} \mathrm{C}$ during the summer months $[4,5]$.

According to the Sustainable Urban Mobility Program for the Monterrey Metropolitan Area 2020 (PIMUS, by its acronym in Spanish), the mode share (the percentage of travellers using a particular type of transportation) is $46 \%$ for cars, $20 \%$ for public transport, $19 \%$ for walking, $6 \%$ for transport network companies (TNCs) and taxis, $5 \%$ for institutional transportation, $2 \%$ for school transport, $0.8 \%$ for bicycles and $0.3 \%$ others. Furthermore, the travel purposes are $44 \%$ work, $18 \%$ education, $14 \%$ shopping, $12 \%$ accompany or picking up someone, $4 \%$ recreation, $3 \%$ health and $5 \%$ other [6].

The elevated number of vehicles in the city, together with an inefficient urban design, results in traffic congestions, which at the same time contribute to an increase in carbon and co-pollutant emissions due to the repetitive motor starts and stops [7]. This worsens Monterrey's pollution. Citizens from the MMZ also suffer from accessibility disparity when it comes to their mobility options, which is related to socio-economic factors. The higher the income, the more options the citizens have for travelling within the city and to access certain opportunities. This disparity is more evident in such a vehicle-oriented urban morphology [3].

There have been different efforts and projects to improve urban accessibility within the MMZ; an example is Distrito Tec, which is a project led by the Instituto Tecnológico de Monterrey (ITESM) university in collaboration with the community in the vicinity of the campus and local authorities. It aims to improve the urban environment near the university campus for citizens and campus users. This project is one of the City Improvement Districts (CIDs) implemented in Monterrey, emerging as proposals of urban regeneration to increase citizen engagement at strategic points of the MMZ. Figure 1 shows the facilities of the ITESM Monterrey Campus, allotments and green areas within Distrito Tec.

This particular CID is an area of 452 hectares located at the south of Monterrey City. It has a population of 26,333 inhabitants and comprises 24 surrounding neighbourhoods of the university [8]. Distrito Tec is of special interest to investors and local property owners due to the high demand of services (food, lodging, leisure, entertainment, among others) required by the community of students, professors and collaborators at Tecnológico de Monterrey. This dynamic environment results from the proximity and integration of this polygon to the university, and it is an interesting small-scale representation of an urban environment [9]. 


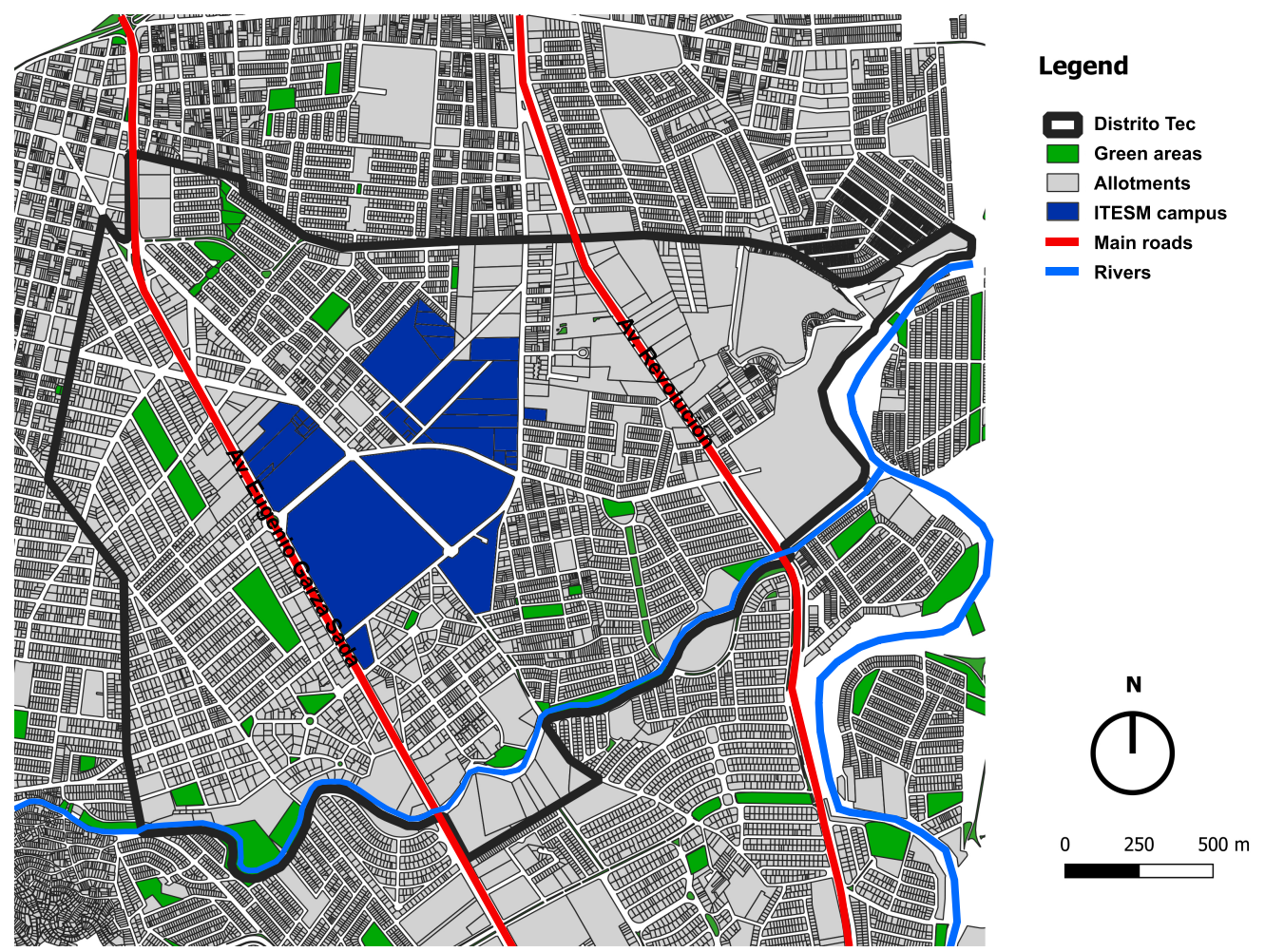

Figure 1. Urban representation of Distrito Tec, in the City of Monterrey.

In response to the current increasing mobility problems in the MMZ, the present study proposes the analysis of urban accessibility using the Urban Accessibility Computer (UrMoAC) software developed by the German Aerospace Centre (DLR) [10]. The analysis was performed at two scales: (i) the metropolitan level (entire MMZ) and (ii) the local level, using the Distrito Tec Area (neighbourhoods in the vicinity of the Tecnológico de Monterrey university campus). Both scales have the objective to measure accessibility to destinations that most people frequently visit: schools, main employment centres, supermarkets and hospitals. Nevertheless, each scale of analysis has a specific scope and methodology to evaluate accessibility, as will be explained in Section 2.

It is important to mention that the whole social, economic and, to a certain extent, political structure of the city behaves as a metropolitan area, despite the actual political divisions. Therefore, it is key to comprehend the urban needs at the different scales to develop public policies and interventions that respond to specific issues.

In contrast to traditional urban planning theories and procedures, taking an approach from urban accessibility has been demonstrated to have an incredible potential to better understand the systemic and complex nature of cities [11]. According to [12], accessibility can be defined as the "extent to which the land use-transport system enables (groups of) individuals or goods to reach activities or destinations by means of (combination of) transport mode(s)". Furthermore, it has been argued that accessibility consists of four components: (I) transport, (II) land use, (III) temporal and (IV) individual [12]. Accessibility concentrates on studying and evaluating how people access, or not, the different opportunities (destinations) of the urban realm, by taking into account the distributions of activity locations and the available transport modes within a given area.

It is important to mention that there are certain variables that affect the peoples' behaviour when accessing opportunities in the city, which go beyond the availability of activity locations and transport alternatives. These variables can be related to social preference (e.g., a family prefers one school over another), demographic (group ages of the population in a specific area), entitlement to health services (whether a person has the right to receive attention at a specific hospital or not), or level of service of the opportunities (this has to do with opening hours, capacity and type of service provided), among others. 
It is crucial to fully analyse these variables before suggesting or making any interventions in the land use or mobility network of a given area, as they drastically affect the level of accessibility for the local population. Nevertheless, to do so goes beyond the scope of work of the current research project, which aims to provide a preliminary diagnosis of urban accessibility at the metropolitan and local level and relate it, only for the local level, to the 15 minutes city planning approach.

"La ville du quart d'heure" or 15 minutes city is an urban concept developed by Carlos Moreno where he imagines a city where every urban dweller can access her/his daily necessities within a maximum of $15 \mathrm{~min}$ of travel time by foot or bicycle [13]. The 15 minutes city implies an urban shift from car-oriented cities to proximity-based cities, upon the idea that "quality of urban life is inversely proportional to the amount of time invested in transportation" [13].

In this sense, the 15 minutes city concept emphasizes urban planning at the local (neighbourhood) level and concentrates on promoting accessibility rather than mobility. The focus is on diversifying land use to guarantee that every part of the city has enough green space, housing, public services, recreation areas, and jobs, at the local level, instead of developing more or higher capacity transport networks. Micromobility plays a key role in 15 minutes cities, as it promotes people's ability to access all local opportunities by walking or by using a bicycle. Hence, there is a special interest in creating open streets that foster activity in the public space and make walking and cycling safe and comfortable [13].

As a result of recent planning trends such as the 15 minutes city and a transition of transport modes from vehicles to active mobility (such as walking, cycling, etc.), accessibility has taken a spotlight in the planning paradigm by encouraging ideas such as mobilising people rather than motorised vehicles; creating access, not mobility; and thinking first at the local level [14].

To analyse to what extent Mexican cities are prepared to become accessible or $15 \mathrm{~min}$ utes cities and have a safe, comfortable, and realistic transition to active mobility, it is necessary to understand the transport modes and the availability of activity locations, as well as cultural, economic, political and social factors that may promote or oppose such transformation. Hence, the use of urban accessibility measures represents an adequate approach to comprehend travel times and distances and their implications in a social, economic, and environmental dimension. The results represent a key input to detect accessibility issues and develop solutions for them. They also are usable knowledge that can be easily transmitted to the local population to socialise and cocreate interventions, projects, and public policies that can transform the local environment into a safer, more livable, affordable, accessible and sustainable place.

Finally, it must be said that large Latin American cities have specific socio-economic and spatial characteristics that make them very different from cities of similar sizes in other parts of the world [15]. Recognising and working with these specific characteristics has been an important part of the development of the project, to suggest and reach results that are relevant and tailor-made for the nature and context of the MMZ and Distrito Tec.

\section{Materials and Methods}

\subsection{Software}

Urban Mobility Accessibility Computer (UrMoAC) is an open-source tool developed by the German Aerospace Centre (DLR) [10] to compute accessibility measures within a geographical area, which can be aggregated for variable areas. UrMoAC can calculate, among others, the minimum time and distance required to reach the nearest specified destination (places such as hospitals, schools, parks, industries, etc.) using a specific transport mode or a combination of them (walking, cycling, motorised vehicles, and public transport), while taking into consideration the real road network and its constraints (speed limits, directions, and modes of transport). UrMoAC is a command-line tool written in the Java programming language, which reads its inputs from a PostgreSQL/PostGIS database. 
UrMoAC was selected as the most suitable tool to perform the required accessibility analysis since it provides accurate and disaggregated results based on real distances and close-to-reality transportation behaviours. Furthermore, the open-source QGis software was used to visualise the information obtained from UrMoAC [16].

\subsection{Data Processing}

The current project was based on two scales of analysis. The first is at the metropolitan level, which aims to highlight and demonstrate the diverging levels of accessibility in the $\mathrm{MMZ}$ and relate them to relevant urban planning paradigms and socio-economic indicators such as the marginalisation levels. The second is at the local level, considering the Distrito Tec Area. Here, the objective was to analyse the accessibility levels to main employment centres, schools, supermarkets, and hospitals, travelling by foot or bicycle, to determine whether the area can be, or not, considered as a 15 minutes city.

For the current analysis, UrMoAC was programmed to start the measurement from urban blocks (origins) to several different destinations (hospitals, schools, supermarkets, and main employments centres). It is important to mention that there are socio-economic factors, such as social preference and willingness to pay, that can affect the decision of people to access one destination over another. Specifically, higher-income social groups tend to prefer private hospitals and schools to fulfil their health and education needs. In contrast, public services usually have access limitations related to the capacity of the building, level of service, entitlement, opening hours, working days, demand, among others. Including all these variables in the analysis goes beyond the scope of work from the current research project, as it aims to provide a preliminary approach to urban accessibility based on the supply of land uses and transport networks at different scales. In this sense, only public hospitals and schools were taken into account, embracing the idea that public establishments are available for everyone despite their income.

The transport modes used for the computation were either walking (with an average speed of $3.6 \mathrm{~km} / \mathrm{h}$ ) or bicycle (average speed of $12 \mathrm{~km} / \mathrm{h}$ ) to analyse to what extent the $\mathrm{MMZ}$ is ready to shift from car-oriented mobility to generating accessibility through micromobility and proximity-based land use planning. The aforementioned average speeds for each transport mode are the ones proposed by the UrMoAC tool [10]. Public Transport was not considered as it requires General Transit Feed Specification (GTFS) data files to run the accessibility computation, which are not currently available for the areas of study analysed in this work.

As mentioned before, the computation was designed to start every measurement from urban blocks. Depending on the measurement desired, the destinations would vary considering either: the closest available, a specific number of destinations that can be reached (e.g., the five nearest hospitals), or with a 15 min travel time constraint to see how many destinations are available within that travel time. The reasons for generating different measurements were to demonstrate UrMoAC's capacity to compute diverse and relevant results, to integrate social and capacity factors into the measurement (e.g., one school alone cannot fulfil the entire education demand of a given district; therefore, more than one has to be included) and to analyse the results from different approaches that provide useful insights about the accessibility of the study area.

For the results to be legible, understandable, and useful, the individual results from each block were aggregated into Basic Geostatistical Areas (AGEBs, by its acronym in Spanish) and then mapped. The AGEBs are the basic aggregation areas used by the National Institute of Statistics and Geography (INEGI, by its acronym in Spanish) census; therefore, they are an unit of analysis widely used for mapping purposes in Mexico.

For the realisation of this project, the following data were gathered: a compendium of the urban geostatistical cartography of Nuevo León (Mexico) state (from 2016, as it is the most recent version), the urban block subdivision of the 18 municipalities that form the MMZ, the National Statistical Directory of Economic Units 2019 (DENUE, by its acronym in Spanish), and the OpenStreetMap road network from 2021. 
Table 1 shows the databases of the variables (municipalities, blocks, AGEBs, DENUE, and roads), the institutions, and the URLs for all the gathered data in this study.

Table 1. Databases and URLs of the used resources in this study.

\begin{tabular}{cccl}
\hline Variable & Database & Institution & URL (All Data Was Accessed on 20 February 2021) \\
\hline Municipalities & INEGI & INEGI & $\mathrm{https} / /$ www.inegi.org.mx/app/biblioteca / ficha.html?upc=702825218867 \\
Blocks & INEGI & INEGI & $\mathrm{https://www.inegi.org.mx/app/biblioteca} \mathrm{/} \mathrm{ficha.html?upc=702825218867}$ \\
AGEBs & INEGI & INEGI & $\mathrm{https} / /$ www.inegi.org.mx/app/biblioteca/ficha.html?upc=702825218867 \\
DENUE & DENUE & INEGI & $\mathrm{https://www.inegi.org.mx/app/descarga/default.html}$ \\
Roads & OSM & OSMF & $\mathrm{https://www.openstreetmap.org/ \# map=10/24.6488/-100.5263}$ \\
\hline
\end{tabular}

The DENUE is elaborated by INEGI and offers a large compendium of all the economic activities registered within the Mexican territory, which can be categorised according to the North American Industry Classification System (NAICS). The NAICS is a standard created to allow high comparability in business statistics among North American countries (Canada, USA, and Mexico). For this study, the categories displayed in Table 2 were analysed.

Table 2. Categories of the analysed economical activities, according to the NAICS.

\begin{tabular}{|c|c|c|}
\hline Code & Category & What Does It Include? \\
\hline 611112 & Public sector preschools & $\begin{array}{l}\text { Economic units of the public sector which are mainly dedicated to providing } \\
\text { preschool education including indigenous, and community types. }\end{array}$ \\
\hline 611122 & Public sector primary schools & $\begin{array}{l}\text { Economic units of the public sector which are mainly dedicated to providing } \\
\text { primary education including indigenous, community, and adult types. }\end{array}$ \\
\hline 611132 & Public sector general secondary & $\begin{array}{l}\text { Economic units of the public sector which are mainly dedicated to providing } \\
\text { secondary education including tele-secondary (televised lessons), community, and } \\
\text { adult types. }\end{array}$ \\
\hline 611142 & $\begin{array}{l}\text { Public sector } \\
\text { technical secondary }\end{array}$ & $\begin{array}{l}\text { Economic units of the public sector which are mainly dedicated to providing } \\
\text { technical secondary education including indigenous types. }\end{array}$ \\
\hline 611152 & Public sector terminal technical & $\begin{array}{l}\text { Economic units of the public sector which are mainly dedicated to providing } \\
\text { technical high school education of a terminal nature. }\end{array}$ \\
\hline 611162 & Public sector high schools & $\begin{array}{l}\text { Economic units of the public sector which are mainly dedicated to providing general } \\
\text { or technical baccalaureate education, of a preparatory nature, including } \\
\text { tele-baccalaureate (televised lessons). }\end{array}$ \\
\hline 622112 & General public sector hospitals & $\begin{array}{l}\text { Economic units of the public sector which are mainly dedicated to providing } \\
\text { medical services for a wide range of diseases among children, women, the elderly, or } \\
\text { patients in general. These economic units have facilities for the hospitalisation of } \\
\text { patients and are known as general, paediatric, geriatric, and women's } \\
\text { disease hospitals. }\end{array}$ \\
\hline 622212 & $\begin{array}{l}\text { Public sector addiction medical } \\
\text { services and psychiatric } \\
\text { hospitals }\end{array}$ & $\begin{array}{l}\text { Economic units of the public sector which are mainly dedicated to providing } \\
\text { treatment to patients who require hospitalisation due to psychological disorders } \\
\text { and addiction. }\end{array}$ \\
\hline 622312 & $\begin{array}{l}\text { Public sector hospitals of } \\
\text { services for other medical } \\
\text { specialties }\end{array}$ & $\begin{array}{l}\text { Economic units of the public sector which are dedicated primarily to the care of } \\
\text { specific diseases or the condition of an apparatus or system. These economic units } \\
\text { have facilities for the hospitalisation of patients and are known as oncology, } \\
\text { gynaecological-obstetric, pneumonia, and cardiology hospitals. }\end{array}$ \\
\hline 462111 & Retail trade supermarkets & $\begin{array}{l}\text { Economic units (supermarkets) which are mainly dedicated to the retail trade of a } \\
\text { wide variety of products, such as food, clothing, cleaning supplies and household } \\
\text { items, organised into sections or specialised exhibition areas that facilitate direct } \\
\text { access by the public to the goods. }\end{array}$ \\
\hline
\end{tabular}

For the metropolitan-level analysis, the following accessibility measures were performed: number of employments centres with 51 or more employees accessible within 
a 15 min travel time, the distance and time to the nearest public school (including all levels from preschool to high school), and nearest hospital (including codes 622112, 622212 and 622312).

For the Distrito Tec's analysis, the computations were: number of employment centres with 51 or more employees accessible within a $15 \mathrm{~min}$ travel time, the number of retail trade supermarkets available within a $15 \mathrm{~min}$ travel time, and the time required to access the five nearest schools or hospitals; here, an individual study was conducted for each category mentioned in Table 2.

The aforementioned measurements were evaluated under the following (see Table 3) criteria, which were determined in compliance with each transport mode's average speed (according to UrMoAC) and the cumulative opportunity accessibility metric (where more opportunities in the surroundings relate to higher accessibility levels) [17]. It is important to highlight the complexity of a standardised rating scale for the number of destinations reachable within a specific time or distance, when comparing different services, as socio-economic and demographic features must be considered to develop an accurate measurement. Therefore, the current research project performed a preliminary approach and diagnosis by evaluating the number of destinations available within a $15 \mathrm{~min}$ travel time either by bicycle or walking. Comparisons of accessibility across different services were not evaluated.

Table 3. Standardised rating scale.

\begin{tabular}{cccc}
\hline Scale (Accessibility) & Time (min) & Distance Cycling (m) & Distance Walking (m) \\
\hline Low & $>30$ & $>6000$ & $>1800$ \\
Medium & $15-30$ & $3000-6000$ & $900-1800$ \\
High & $0-15$ & $0-3000$ & $0-900$ \\
\hline
\end{tabular}

\subsection{Study Area}

\subsubsection{Monterrey Metropolitan Area}

With 74 metropolitan areas in 2015, as declared by the National Population Council (CONAPO, by its acronym in Spanish), the conformation of large metropolitan areas has been one of the main urbanisation trends in Mexico since the 1950s Century [18]. The creation of metropolitan areas has been fuelled by the centralisation of economic activities, such as industries and services, in large- and, to a lower extent, middle-sized cities. These cities grew demographically from rural to urban migration, led by people who were looking for better employment opportunities and living conditions. Yet, the metropolitan areas have failed to achieve an urban development that can cope, in a sustainable manner, with the social, economic, and environmental demands [18].

The marginalisation index is an indicator used by CONAPO that serves to demonstrate how metropolitan areas have divergent conditions and how planning paradigms and processes have failed to create a city where all inhabitants have the same conditions and access to opportunities [19]. It relates to a lack of social opportunities and the absence of the capacity to generate them, as well as to deprivation and inaccessibility of basic goods and services. This indicator is based on 10 different socio-economic factors [19]:

1. Percentage of the population within 6 and $14 \mathrm{y}$ who do not attend school;

2. Percentage of the population $15 \mathrm{y}$ or older who have not completed their basic education;

3. Percentage of the population without entitlement to access the public health system;

4. Percentage of dead children from women between 15 and $49 \mathrm{y}$;

5. Percentage of particular occupied households without running water;

6. Percentage of particular occupied households without drainage connected to the public network or a septic tank;

7. Percentage of particular occupied households without a toilet connected to running water;

8. Percentage of particular occupied households with dirt floors; 
9. Percentage of particular occupied households with some level of overcrowding;

10. Percentage of particular occupied households without a fridge.

Figure 2 shows the marginalisation levels in the MMZ according to the CONAPO [20], as well as the location of Distrito Tec within the MMZ. It can be observed that most of the AGEBs in the MMZ lie within the low $(22.91 \%)$ and very low $(41.42 \%)$ marginalisation levels, with few classified as medium $(20.76 \%)$, high $(4 \%)$, or very high $(1.63 \%)$. There are $9.19 \%$ of the AGEBs that are not categorised. It is worth mentioning that the regions with higher marginalisation levels are located in the outskirts of the MMZ, usually places with low levels of accessibility.

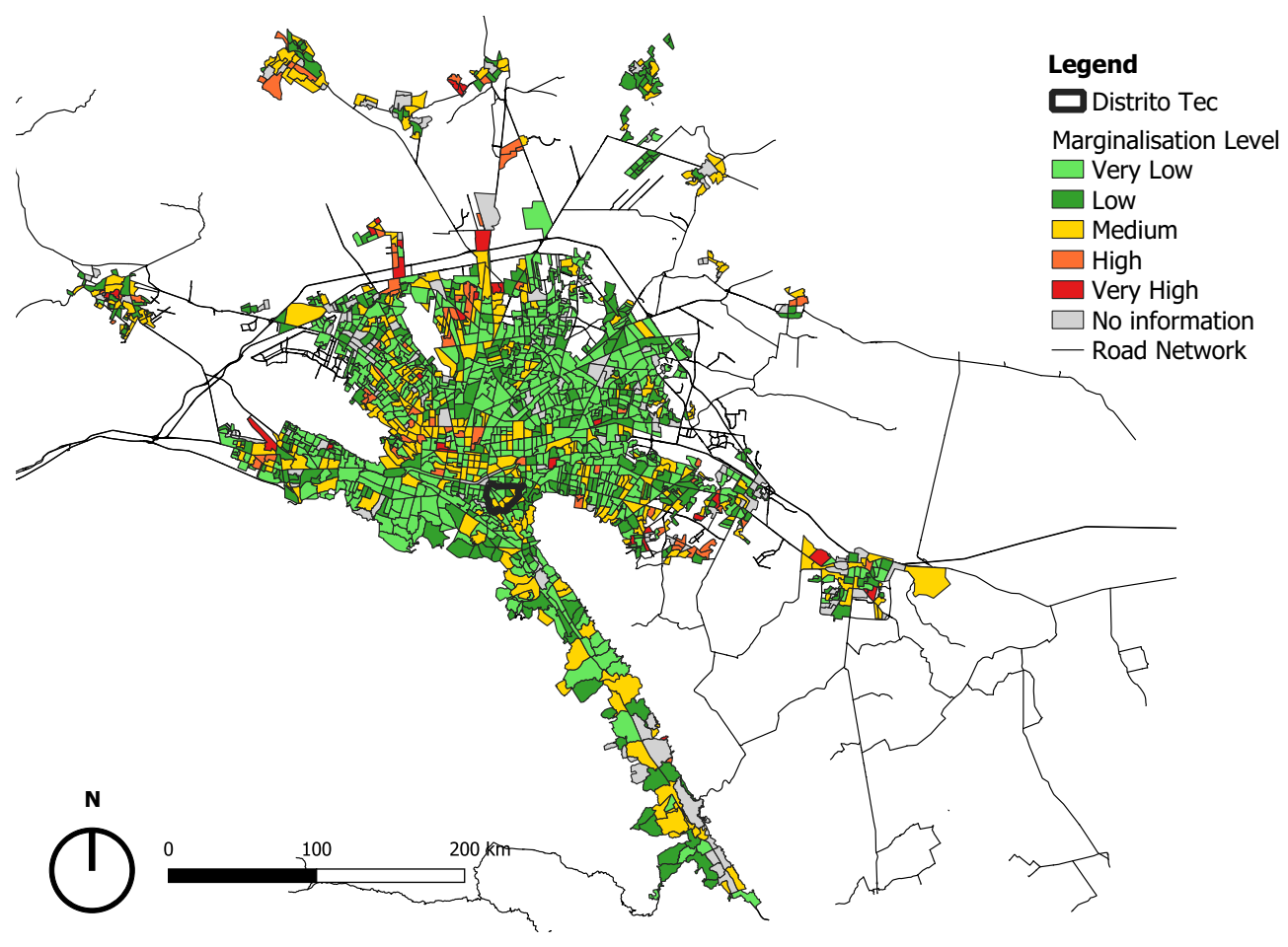

Figure 2. Marginalisation levels in the Monterrey Metropolitan Zone (MMZ).

Clearly, the MMZ is not an exception to the challenges that Mexican metropolitan areas face. There exists room for improvement in terms of creating central and well-located social housing, diversifying economic clusters throughout the city to promote decentralisation, and rethinking urban planning concerning land uses to guarantee enough supply to satisfy local needs.

Furthermore, changing demographics have to be taken into account. Figure 3 displays the population distribution in the MMZ as in Monterrey Municipality. The MMZ population has a pyramidal shape where most of its inhabitants are $40 \mathrm{y}$ or younger. Even though the distribution of the Monterrey Municipality is similar to the one of the MMZ, there is a faster shift towards a more rectangular shape, meaning that the city is facing a stationary growth [21]. This population trend will result in a decreasing demand for infrastructure related to children (such as schools and kindergartens) and an increase in demand in infrastructure related to elderly persons (such as hospitals and retirement/nursing homes).

The analysis at the metropolitan level has the objective to demonstrate the performance of the MMZ in terms of accessibility to different location types. The results will allow urban planners and policymakers to identify underperforming areas in relationship to specific variables. This information can then be translated into a hierarchy-based intervention plan, starting with the areas with lower levels of accessibility. Hence, the analysis at the metropolitan level does not relate to the 15 minutes city concept, as a broad analysis of each area of the city would be required and the addition of more variables (destinations) will be needed. Nevertheless, some of the results can provide useful insights and findings 
to determine whether certain areas of the city meet the 15 min travel time parameters for a specific variable.
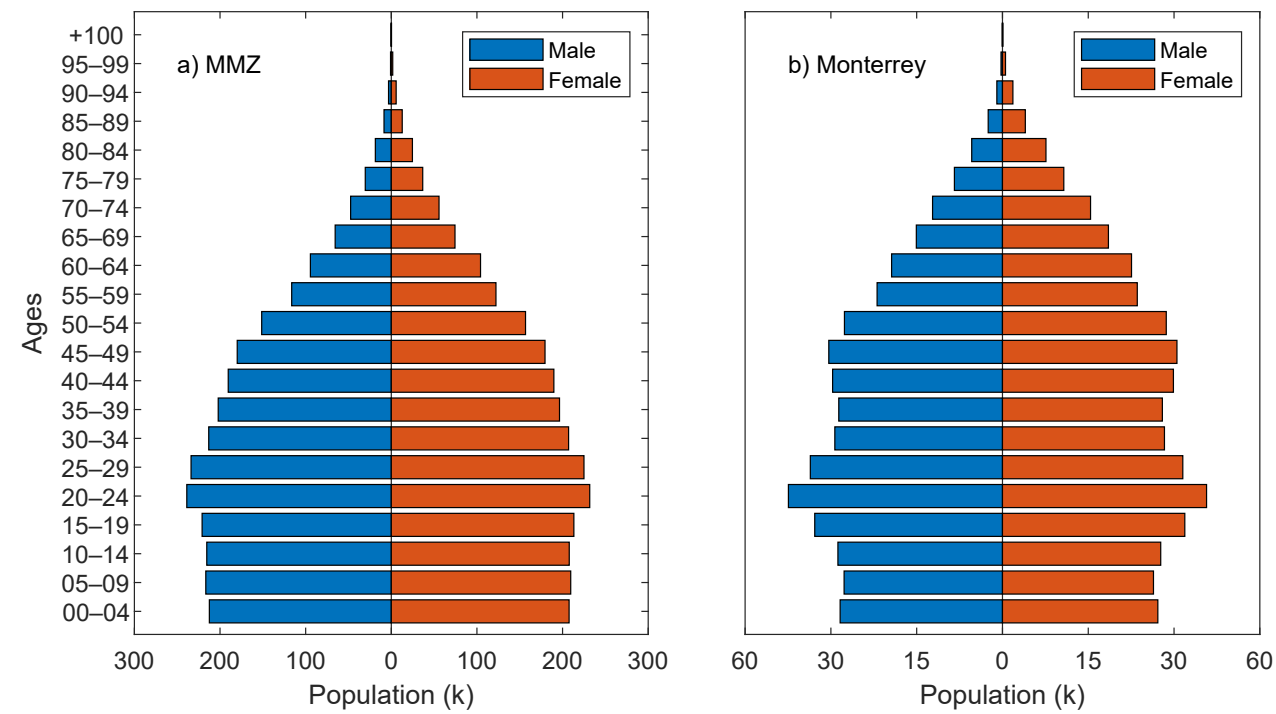

Figure 3. Population distribution (thousands) by ages $0-100+$ in the MMZ (a) and Monterrey (b).

The current research project departed from analysing accessibility at a metropolitan scale, to understand and assess the socio-spatial relationships that drive the city. Hence, the two major destinations that promote travel were studied: main employment centres and public schools. Additionally, a variable for public hospitals was added, as it was considered that access to health is key to promoting better living conditions.

\subsubsection{Distrito Tec Area}

By considering a smaller scale of analysis, the level of complexity of the area reduces, allowing incorporating new variables and destinations within the scope of work of the current research project. Therefore, the local area analysis, considering Distrito Tec (See Figure 1) as the study area, can take a preliminary approach to analyse to what extent Distrito Tec meets the requirements of accessibility to different destinations, using walking or cycling as the transport modes, to be considered a 15 minutes city.

It is important to mention that Distrito Tec is located within a central area of the city. Hence, in comparison to other areas, it is considered privileged in terms of its surroundings (see Figure 2). Based on this, it is expected that the levels of accessibility within such an area will be higher than the ones of suburban areas.

The neighbourhoods surrounding the Distrito Tec Area are heterogeneous and affect the levels of accessibility of the area. The same counts for the mobility patterns. Therefore, it is important to give a brief characterisation of each one of them.

According to Figure 4, the northern area has very low to medium marginalisation levels and is mainly residential with single-family zoning. The commercial activities are located on the main avenues and offer some additional services such as community schools.

The eastern area has faced important changes since the 1950s, as it used to have a brick factory that was dismantled to allow several urban renewal processes to happen. There is a contrast between the socio-economic levels of the population. In the neighbourhoods in the vicinity of the brick factory, a low-income worker population predominates; in contrast, on the opposite side of the river, there are high-income gated residential communities. The land use variety is low, with most being residential with single-family zoning. The small numbers of commercial places and services tend to be located around the main avenues where vast shopping centres have been built (e.g., Nuevo Sur shopping mall).

The western area is the oldest, dating to the 1920s. It is characterised by being a middle-income residential area with single-family zoning. Through time, a heterogeneous 
land use mixture has emerged in the area, having many commercial activities and services located on the main avenues.

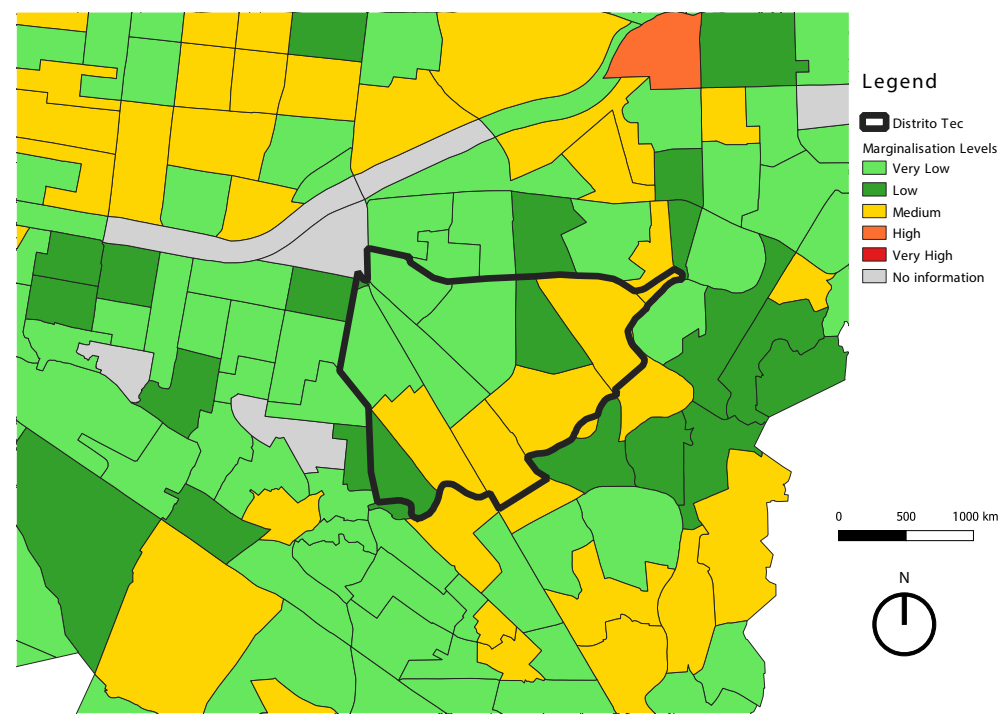

Figure 4. Marginalisation levels in Distrito Tec.

The polygon of Distrito Tec was designed based on the neighbourhoods' boundaries, which are located in the vicinity of the university campus. However, the AGEBs do not fully correspond to such limits; thus, some AGEBs will not be completely encompassed within the polygon. For the current analysis, 11 AGEBs were considered as part of the Distrito Tec Area, as presented in Figure 4.

The first set of variables to be analysed is access to public kindergartens and schools. For this section, a specific accessibility measure was computed for each education level to understand how the local people, depending on their age, are able of accessing education places. Considering that the closest destination might not be able to address the entire demand of the AGEB, as well as social preference factors, the accessibility measures were evaluated for the five closest locations (kindergartens, primary, secondary and high schools).

\section{Analysis and Results}

\subsection{Monterrey Metropolitan Area}

Figure 5 shows the average distance from every AGEB to the closest public schools using bicycles as the transport mode. It can be observed that most of the AGEBs have a public school in a range of less than $1000 \mathrm{~m}$. This is due to the high density of schools (especially primary and secondary) that most areas of the MMZ have. Building schools has been one of the priorities of the authorities, as there is a high demand for them given that Mexican demographics maintain a pyramid structure. This means that there is a considerable amount of people younger than $30 \mathrm{y}$, as observed in Figure 3a,b, which shows the age distribution of the population of the MMZ and Monterrey, respectively, according to the INEGI 2020 census.

Interestingly, many suburban areas that are not even physically integrated into the city have high accessibility levels (e.g., some northern and southwest regions). This phenomenon reduces the travel dependence from suburban areas to central areas to access education.

The south and southeast of the city have the lowest access levels, which relates to the fact that both are high-income areas where residents tend to prefer private schools and that some of these areas were designed and built as gated communities with only residential land use. 


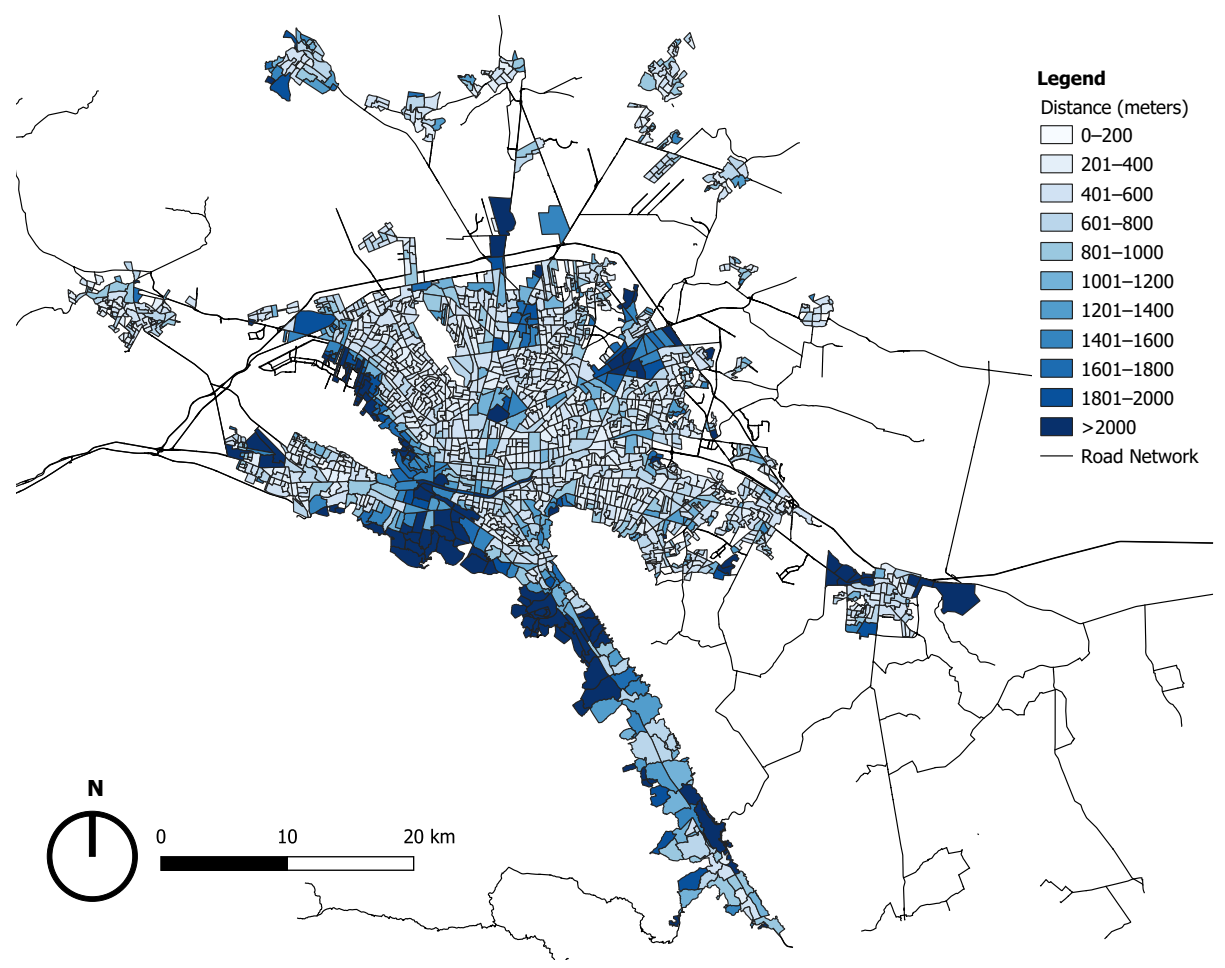

Figure 5. Average distance to the closest public school travelling by bicycle.

Figure 6 compares the performance of the transport modes (bike and walking) in accessing the closest public school at the metropolitan level. The first important thing to highlight is that despite the transport mode used, $75 \%$ of the AGEBs can access a school in less than $10 \mathrm{~min}$. This is related to the high density of schools at the metropolitan level, as observed in Figure 5. By comparing the transport modes, it becomes evident that cycling achieves considerably higher levels of accessibility: while it takes $9.7 \mathrm{~min}$ for $75 \%$ of the AGEBs to reach the closest school by walking, for the same percentage, it only takes $3.5 \mathrm{~min}$ by cycling.

It is important to mention that Figure 5 is just a preliminary approach to understand accessibility to schools; this variable will be disaggregated in the following section, to analyse how access varies depending on each school's education level.

Figure 7 presents the average travel time by AGEB to the closest public hospital by foot. The map shows a considerable divergence of accessibility between AGEBs, with many going beyond the $30 \mathrm{~min}$ travel time, mainly due to the low density or nonexistence of hospitals, predominantly in suburban areas.

Central areas show high access to hospitals. This can be attributed to the historical conformation of the city, which started at the centre and gradually sprawled. Therefore, central areas have existed for longer periods, allowing the authorities to implement through time the necessary health infrastructures in these areas. In contrast, many suburban areas are relatively new, and some have lacked formal planning procedures (people built homes without having any official permit from the government or public administration), while others have been designed following urban paradigms that purposely create isolated and monofunctional areas, such as gated communities.

The southeast of the map represents an excellent example of how planned urban communities can lack access criteria in their planning procedures and how these problems are not exclusive to lower-income areas or highly marginalised ones that have been built without any formal planning. In this sense, what some people think could be a solution (urban planning) can trigger a problem. 


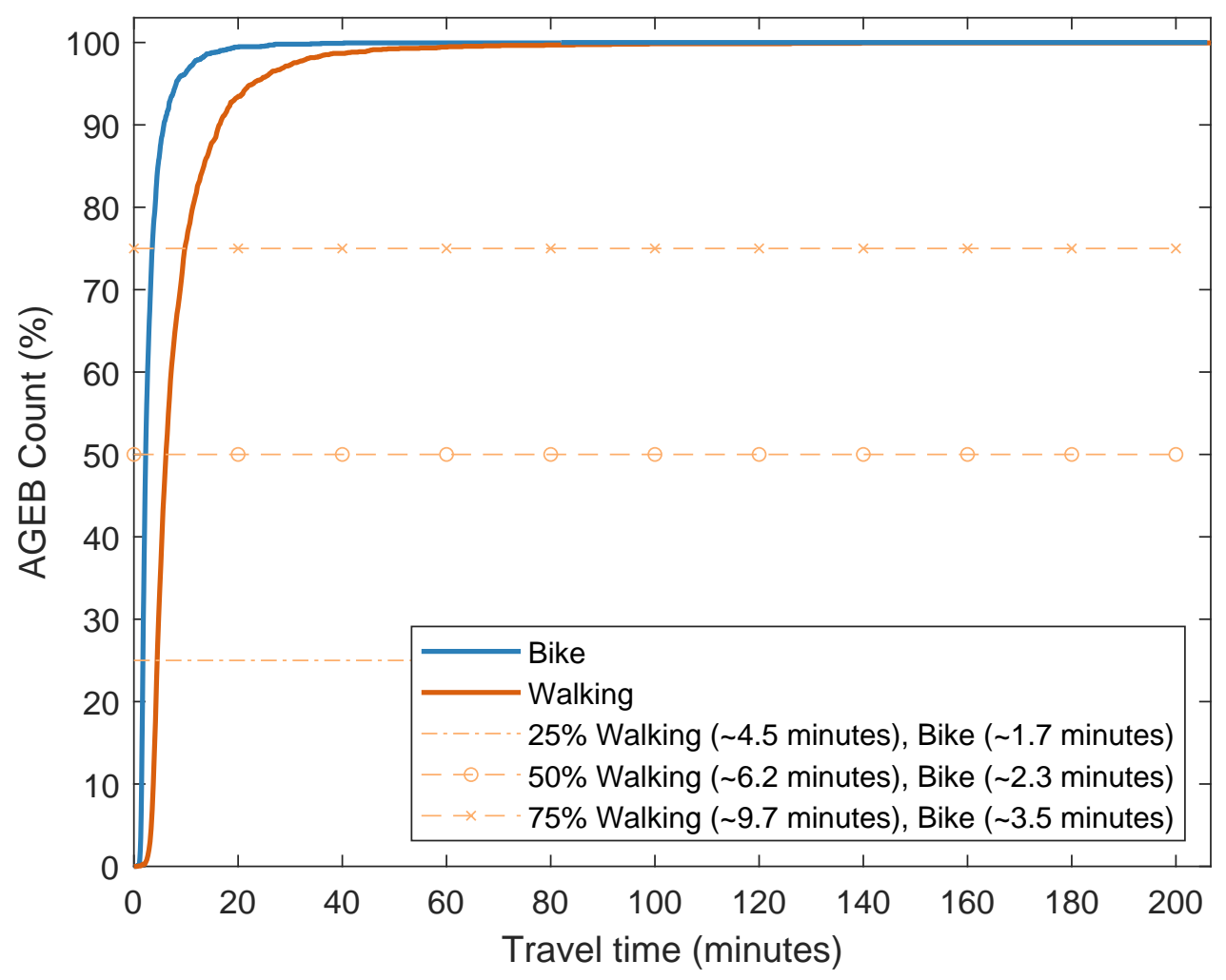

Figure 6. Comparison of the performance of transport modes to access the closest public school at the metropolitan level.

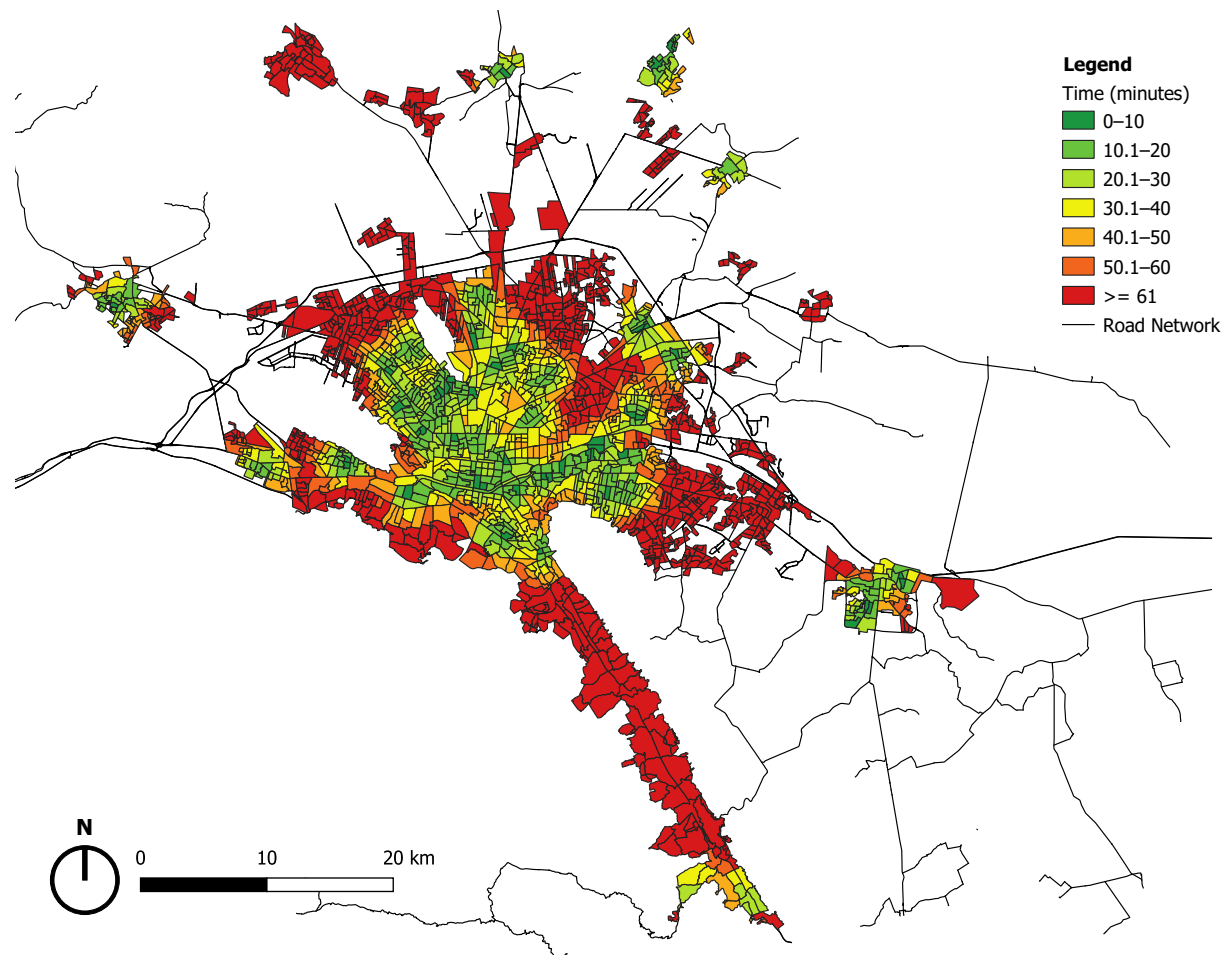

Figure 7. Average travel time (minutes) to the closest public hospital by foot.

The COVID-19 pandemic has demonstrated how important it is to have a robust and accessible healthcare system [22]. Therefore, poor access to health services should be unacceptable, as observed in many AGEBs of the MMZ. The MMZ needs to urgently tackle this problem by developing new public health centres in any area of the city that does not meet the desirable access parameters. 
Figure 8 compares the performance of both transport modes (walking and bicycle) to access the closest public hospital. For this specific variable, the differences between one mode and the other are more evident. This is related to the lower number of destinations available at the metropolitan level (in contrast with Figure 6, the number of hospitals is evidently lower than that of schools). Hence, faster transport modes, such as bicycles, will outperform walking by a considerable margin: for $75 \%$ of the AGEBs to reach the closest public hospital travelling by foot, it takes $46.8 \mathrm{~min}$; in contrast, it only takes $14.7 \mathrm{~min}$ by bicycle.

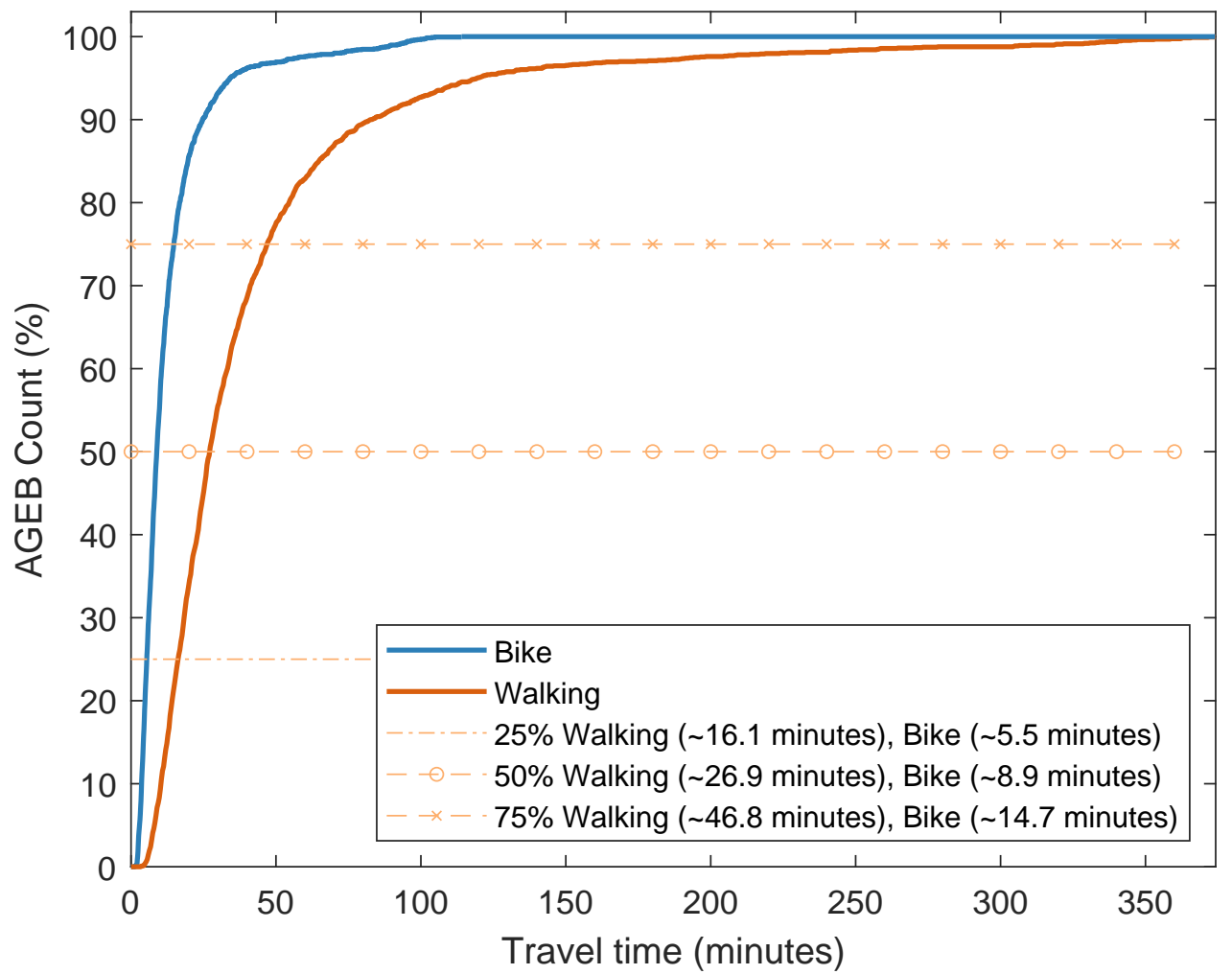

Figure 8. Comparison of the performance of transport modes to access the closest public hospital at the metropolitan level.

Figure 9 shows the number of economic activities that employ 51 persons or more (main employment centres) that can be accessed within a 15 min travel time by bicycle. It can be appreciated that most of the AGEBs with higher levels of accessibility (+73 destinations) are located in the central areas of the city, with a gradual decline towards the outskirts. At first sight, such a result might be perceived as unusual, considering that the MMZ is an industrial city and that most industries are located in suburban areas. Nevertheless, industries usually have very large complexes that occupy vast areas of land and make them separate from one another, reducing access to them in short periods. In contrast, even though they are smaller in size and number of employees, the economic activities that concentrate in central areas of the city (such as commerce and services) require smaller areas of land compared to industries and are located closer to each other.

The reduced number of main employment centres at the northern, western, eastern, and southeast AGEBs implies that residents in those areas have to travel long distances and periods of time to central areas to work, relying heavily on motorised modes of transport. This traffic has high economic, environmental and social costs for the city and its residents, and can be tackled by creating new clusters of economic activities in areas with low access and by improving transport networks, especially public transport. It is important to isolate and analyse each particular case, as some of these areas lack main employment centres given that, historically, they were independent of the city, but the sprawl has reached 
them and forced them to integrate with its economy. Some other areas were lacking main employment centres on purpose, as many of the AGEBs located to the southeast of the MMZ were designed as high-income gated communities (especially golf clubs) with only residential land use. As all the residents from these areas require accessing the opportunities located within central areas, they generate demand for public infrastructure that is extremely expensive and that should not exist if planning policies were to assure land use diversity and accessibility parameters before authorising building permits.

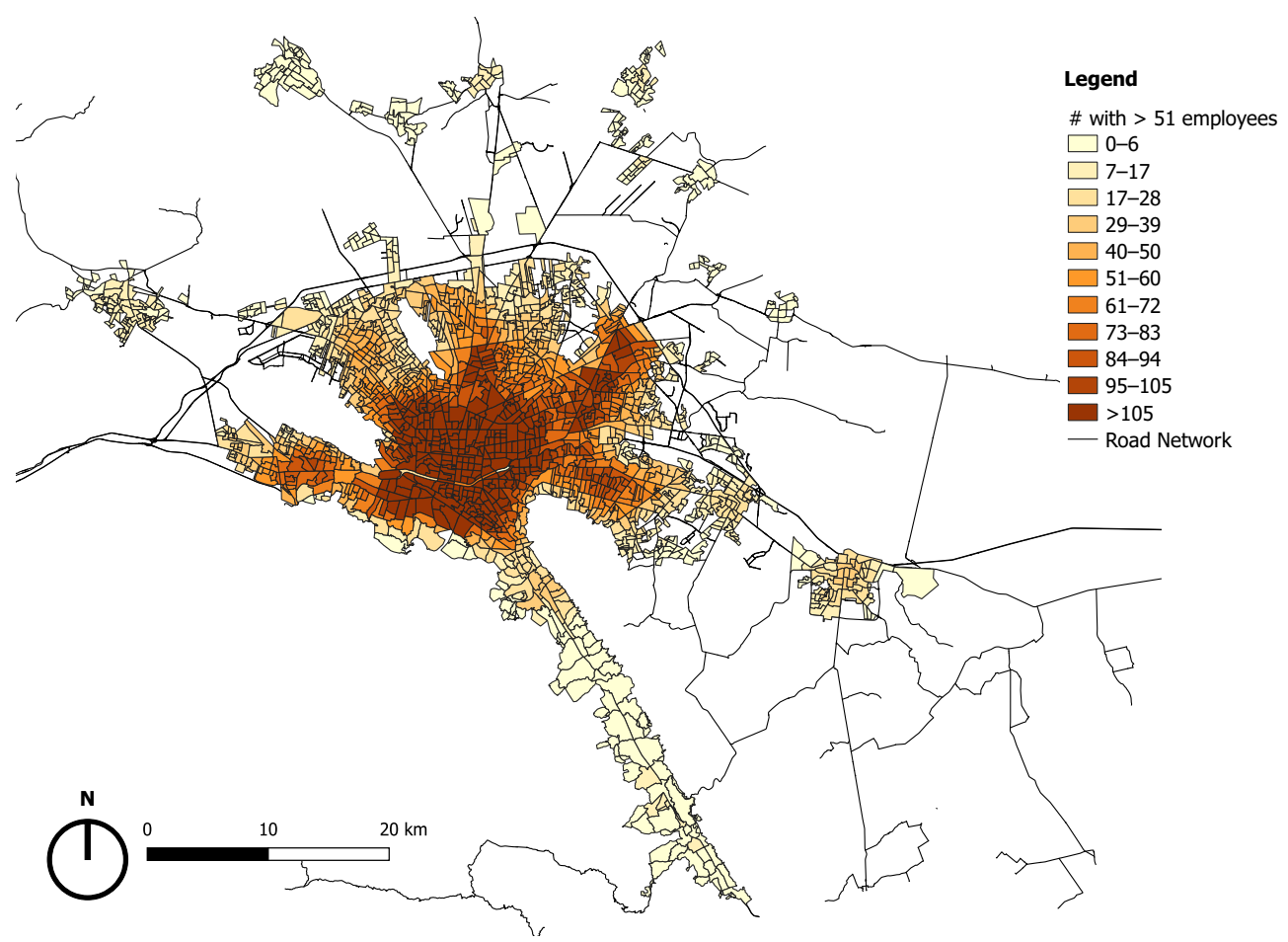

Figure 9. Number of economic activities that employ $\geq 51$ persons within a 15 min travel time by bicycle.

The three variables previously presented demonstrate how complex urban areas truly are and how inaccurate generalisations can be. The present exercise thus serves as a preliminary approach to demonstrate that every city faces many different and particular challenges. Consequently, any solution, in order to generate a beneficial change, must be based on a full understanding of the specific desired conditions in the city.

The current research demonstrates that using accessibility measures is extremely useful for identifying specific needs from different areas of the city and that despite the accessibility measure chosen, the data obtained are relevant. The information generated can be used as a departure point for prioritising interventions and public policies depending on the performance of each area on a given variable. By doing so, much time and many resources can be saved.

This first section of analysis concludes that the levels of accessibility at the metropolitan level are divergent and that they drastically vary, even in the same location, depending on the measured variable. The results are a relevant input to obtain a general diagnosis of the state of the MMZ in terms of accessibility. These results can also be compared to different socio-economic variables, such as marginalisation rates, to better understand the social, economic, political, and environmental factors that drive the city. This information represents a solid departure point to then analyse what happens at smaller scales, without ignoring that each area of the city is bound to metropolitan interrelationships. 


\subsection{Distrito Tec Area}

Figure 10 shows the average time by AGEB to access the five closest public kindergartens. As most children going to kindergartens are not able to cycle, the accessibility measure was computed for travelling by foot. Even though the number of kindergartens within the polygon is low (four), the surrounding areas at the north, west, and southwest have considerably high densities. In contrast, the areas in the east and the southeast have very low densities.

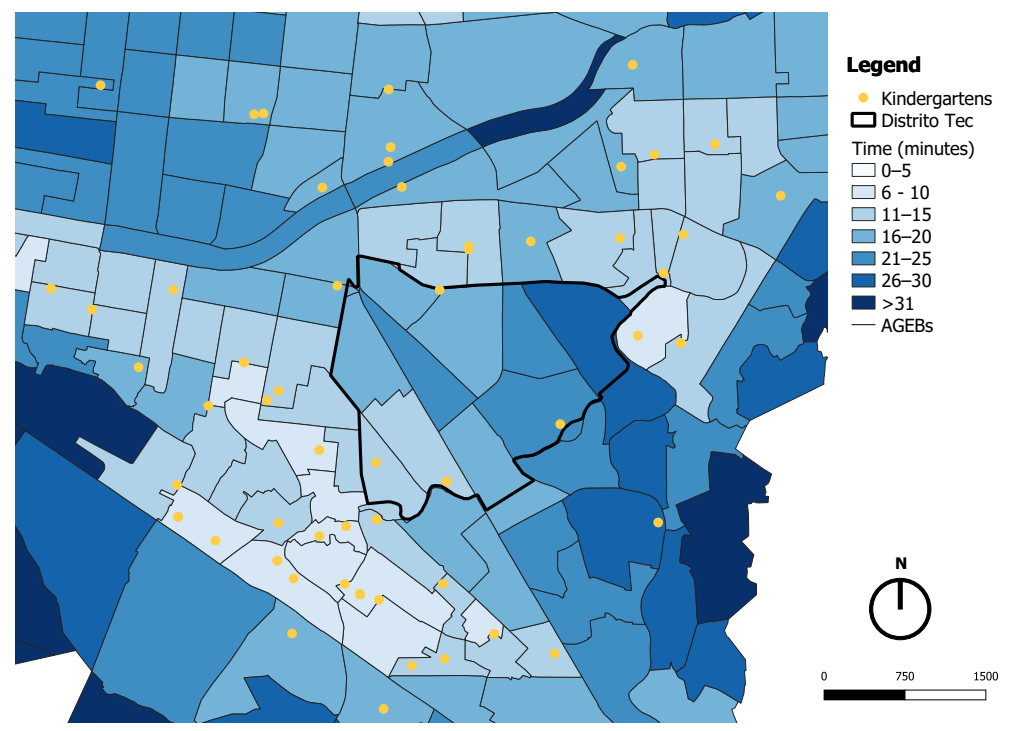

Figure 10. Average time to the 5 closest public kindergartens travelling by foot.

Three of the eleven AGEBs within Distrito Tec meet the constraint to access the closest five kindergartens in a maximum of $15 \mathrm{~min}$, with all three AGEBs in the 11-15 min class. The rest of the AGEBs have considerably higher access times with four AGEBs in the 16-20 min class, three in the 21-25 min class, and one in the 26-30 min class. The lowest accessibility levels are represented in the AGEBs located to the southeast of the polygon. This is due to the relatively low density of destinations in the surrounding areas, especially to the east.

As most AGEBs within the polygon do not meet the 15 min travel time criteria, it can be argued that in terms of access to kindergartens by foot, the Distrito Tec Area cannot be considered a 15 minutes city. Nevertheless, additional information should be collected to know how many children in the Distrito Tec Area are within the age range to go to kindergartens. In the case that this number is low, the computation could be made to the closest kindergarten, as this one could host all the local demand. Such a scenario would considerably increase the levels of accessibility.

Figure 11 presents the average time by AGEB to access the five closest public primary schools by foot. Again, the density of destinations within the Distrito Tec Area is low, with only three schools. Yet, the surrounding areas at the north, northeast, west, and southwest have considerably high densities.

Only three out of eleven AGEBs from the Distrito Tec Area meet travel times of a less than or equal to $15 \mathrm{~min}$. These AGEBs are located on two opposite corners of the polygon (northeast and southwest) and can meet the $15 \mathrm{~min}$ parameters due to the high number of destinations in the outer nearby areas. In contrast, six AGEBs require a travel time of 16-20 $\mathrm{min}$ to reach the closest five destinations. The higher travel time is due to the low number of destinations in central areas of the Distrito Tec Area. Finally, two AGEBs reach the 21-25 min class.

Given the previous results, it can be said that in terms of access to public primary schools, the Distrito Tec does not meet the requirements to be considered a 15 minutes city using only foot as the travel mode. However, by using other modes of transporta- 
tion such as bikes, the travel times would drastically decrease and the accessibility level would increase.

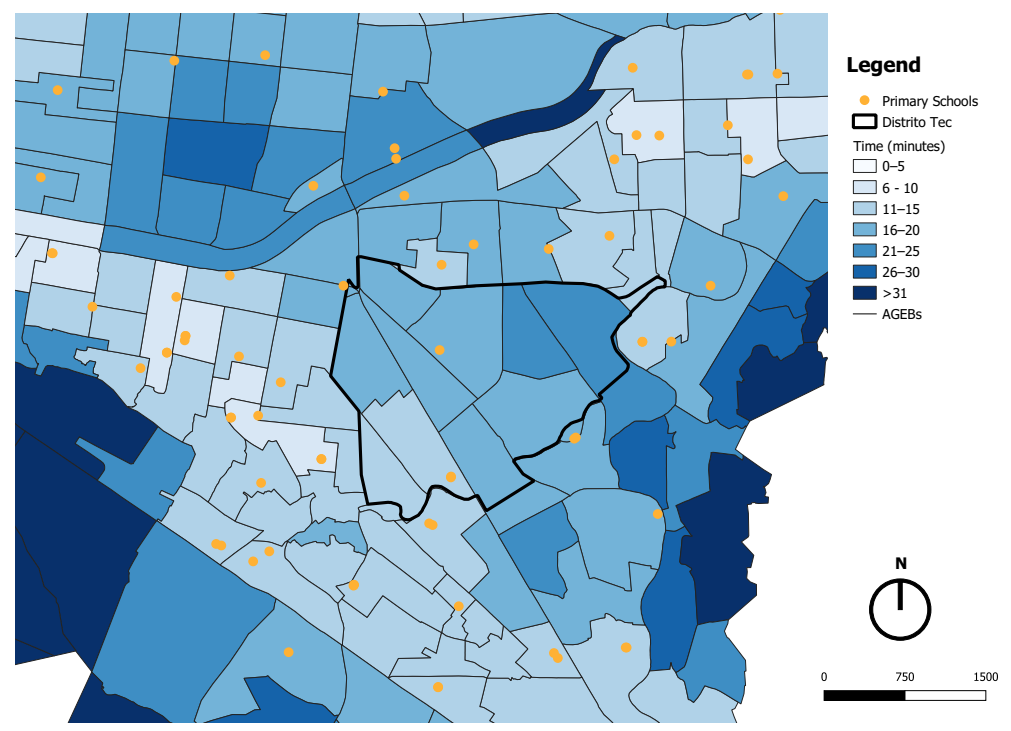

Figure 11. Average time to the 5 closest public primary schools travelling by foot.

As the age groups that attend secondary and high schools usually are able to use bicycles as their main travel mode, the following computations were performed considering bicycle as the transport mode. It is important to bear in mind that the average speed of a person travelling by bike is three-times higher than travelling by foot. Therefore, a much higher number of destinations can be accessed within the same time.

Figure 12 presents the average travel time by AGEB to reach the five closest public secondary schools travelling by bike. Even though the density of destinations in the Distrito Tec Area is extremely low (two) and remains low in the outer areas, the accessibility levels are rather high. All AGEBs can access the closest five destinations in a maximum of $10 \mathrm{~min}$ of travel time.

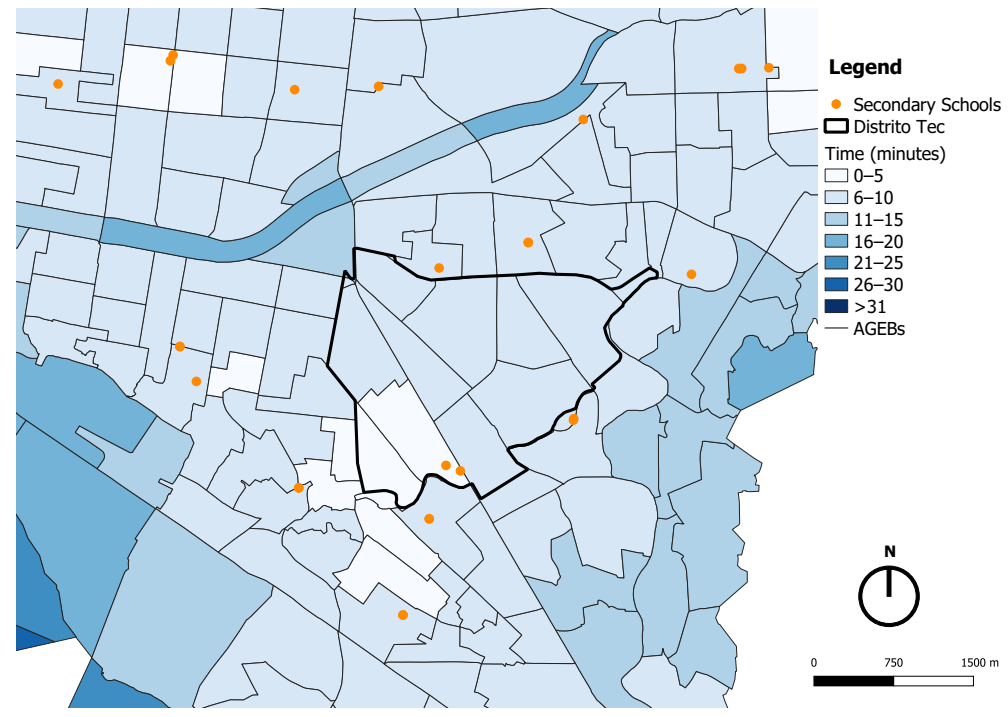

Figure 12. Average time to the 5 closest public secondary schools travelling by bicycle.

From the 11 AGEBs, two are in the lowest class of only 0-5 min of travel time. These AGEBs are located at the southwest border of the polygon, where the only two destinations inside the polygon are located and there are three others in the vicinity. In this sense, it can be said that using bicycles as the main travel mode, the Distrito Tec Area can be considered a 15 minutes city. 
However, when the computation was run using foot as the travel mode, the accessibility levels drastically dropped (See Figure 13). As the share of trips done by bike is very low for the MMZ (only $0.8 \%$ ), the current research project assumed that most of the population attending secondary schools uses other transport modes. In this sense, it is important to highlight the benefits, in terms of accessibility, that fostering the use of bicycles as the main travel mode would bring. One key factor to promote the use of bicycles is to create the safety conditions that users require; thus, implementing cycling lanes and open streets would be mandatory.

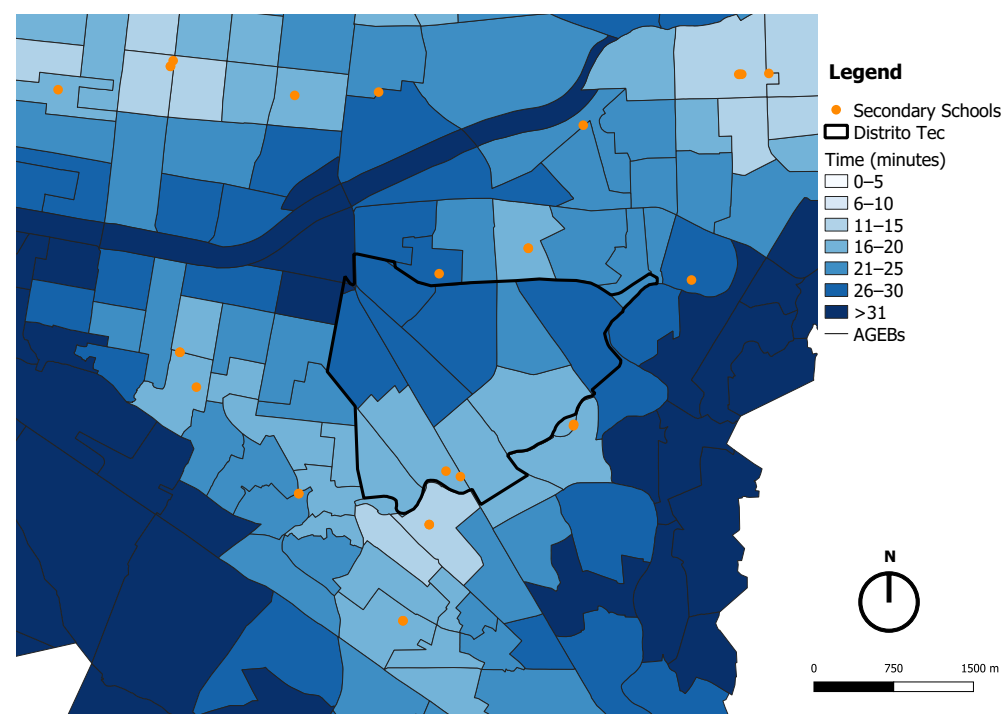

Figure 13. Average time to the 5 closest public secondary schools travelling by foot.

Figure 14 shows the average time by AGEB to reach the five closest public high schools by bike. The density of destinations is extremely low, not only in Distrito Tec (one) but in all the surrounding areas. Hence, the levels of accessibility are significantly lower compared to other variables. Only five out of eleven AGEBs in Distrito Tec can access the five closest destinations in a maximum travel time of $15 \mathrm{~min}$. The other six are in the class above of a 16-20 min travel time.

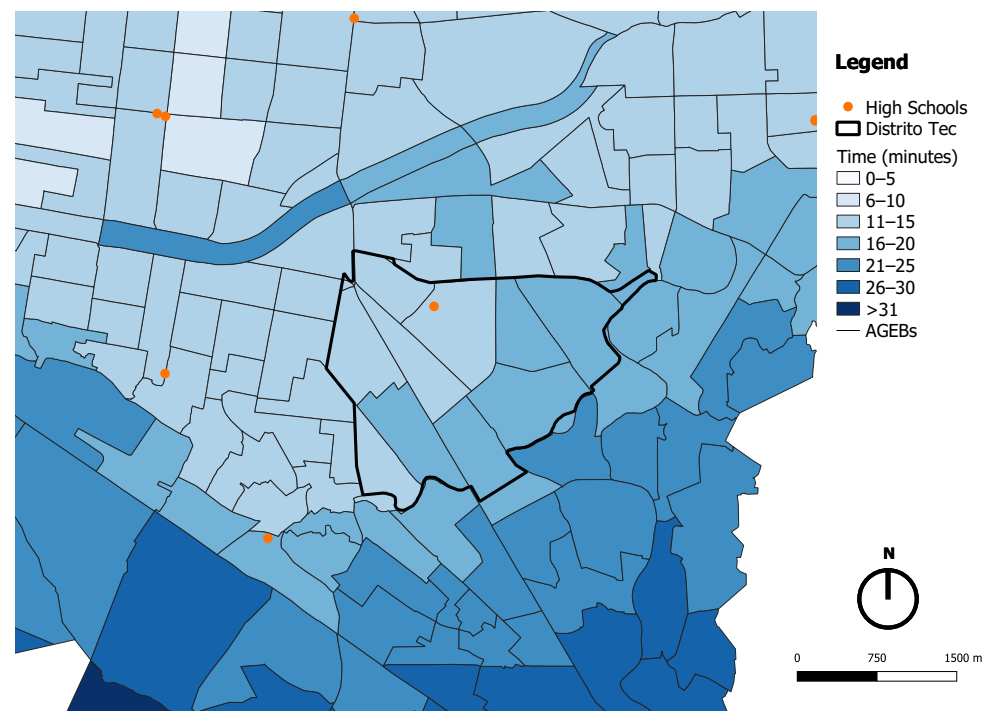

Figure 14. Average time to the 5 closest public high schools travelling by bicycle.

The surrounding areas at the south and east of Distrito Tec have an absolute lack of destinations. As a result, the population living there has to travel through Distrito Tec 
and other areas to reach a public high school. This phenomenon creates traffic in all the surrounding areas and other negative effects.

Again, a computation considering walking as the main travel mode to reach public high schools was included (see Figure 15). The accessibility results are worrying, as all the AGEBs within Distrito Tec, and the surrounding areas, demand $\mathrm{a} \geq 31$ min travel time. Hence, despite which travel mode is taken, it can be argued that the Distrito Tec Area cannot be considered a 15 minutes city regarding access to public high schools.

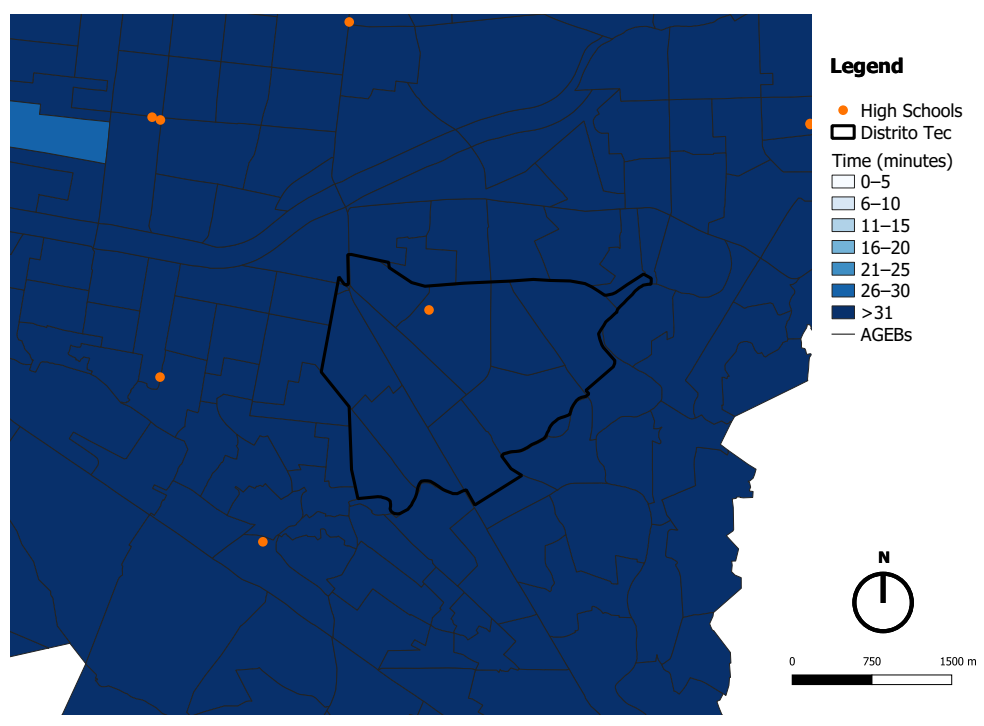

Figure 15. Average time to the 5 closest public high schools travelling by foot.

As seen along with the previous examples, education has many additional variables that have to be taken into consideration such as student capacity, local population age groups, etc., in order to entirely assess how accessibility behaves in the local area. Nevertheless, the accessibility measures are an excellent departing point for understanding the impact of transport modes and services' density on accessibility patterns.

The next variable is access to commercial activities, specifically to supermarkets. Due to a lack of public markets, as seen in many other Mexican cities, Monterrey's population does most of their grocery shopping at supermarkets. Hence, supermarkets are one of the most frequented destinations among the local population, and access to them is key to guaranteeing satisfactory quality of life.

According to the 2020 INEGI census, the average number of inhabitants per household in the MMZ is 3.18 people. This indicator is relevant given that people tend to buy groceries not for one, but for three persons when they go to the supermarket. For that reason, the bought items can be difficult or heavy to carry if the individual travels by foot or bicycle, so many people prefer to use motorised vehicles such as cars or public transport. Nevertheless, if accessibility to supermarkets is high, people would be encouraged to visit supermarkets more often than once per week and buy fewer items per visit so they could avoid the need to use a motorised vehicle.

Access to health is probably one of the most important things for an urban dweller, and this has been exemplified throughout the entire COVID-19 pandemic [22]. However, hospitals are very expensive infrastructures to build and run; hence, they usually have a metropolitan or regional radius of incidence in their planning processes (see Table 4). This section analyses what effects these planning processes have at the local level by measuring the average travel time by foot and bicycle to the closest public general hospital. 
Table 4. Urban equipment regulatory system, recommended service radius. Source: Secretaría de Desarrollo Social (SEDESOL), 1999.

\begin{tabular}{lll}
\hline Type of Hospital & Regional & Urban \\
\hline General Hospital (SSA) & $60 \mathrm{~km}$ (or max. $2 \mathrm{~h})$ & population centre \\
General Hospital (IMSS) & $30 \mathrm{~km}$ to $200 \mathrm{~km}$ (or $30 \mathrm{~min}$ to $5 \mathrm{~h})$ & $1 \mathrm{~h}$ to the population centre \\
Urban Health Centre (SSA) & 5 to $15 \mathrm{~km}$ (or $30 \mathrm{~min})$ & $1 \mathrm{~km}$ (or max. 30 minutes) \\
Medical Unit (ISSSTE) & 30 to $60 \mathrm{~min}$ & $30 \mathrm{~min}$ \\
Medical Unit (IMSS) & $15 \mathrm{~km}$ (or $20 \mathrm{~min})$ & $5 \mathrm{~km}$ (or $10 \mathrm{~min})$ \\
Health Clinic (ISSSTE) & only local scope & $30 \mathrm{~min}$ \\
Hospital Clinic (ISSSTE) & $2 \mathrm{~h} \mathrm{max.}$ & population centre \\
Regional Hospital (ISSTE) & 3 to $4 \mathrm{~h}$ & population centre \\
\hline
\end{tabular}

Figure 16 presents the average travel time by AGEB to the closest public general hospital by foot. The map shows that the number of destinations is extremely low, and within the Distrito Tec Area, there are no public general hospitals whatsoever. The surrounding areas of the polygon show a lack of destinations, with the only exceptions at the northeast area with two available hospitals and the southwest area with also two destinations.

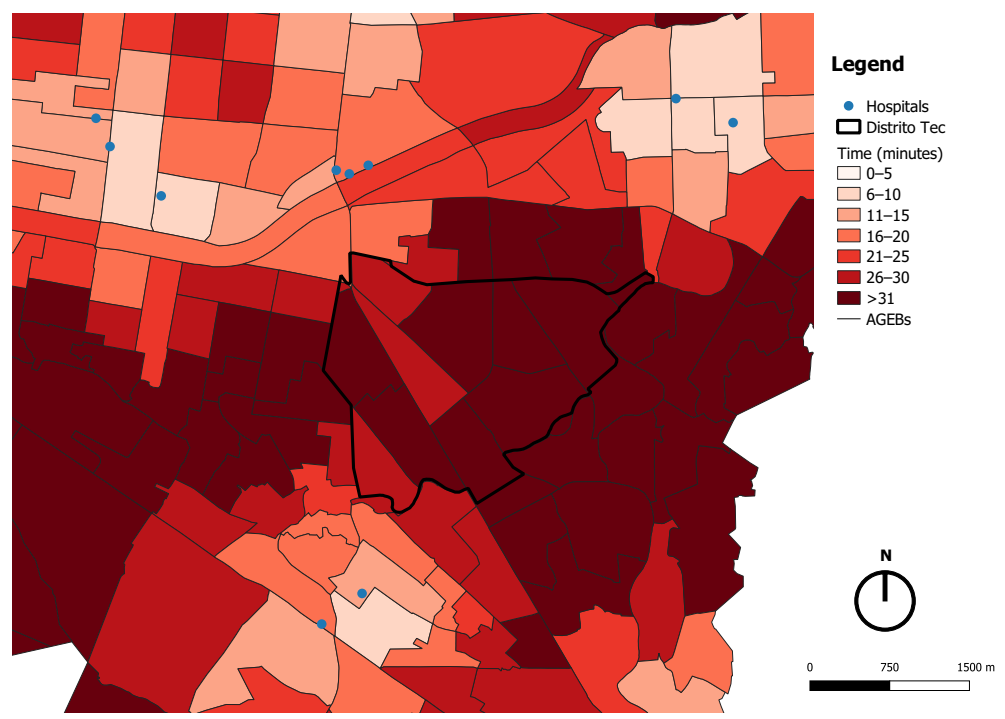

Figure 16. Average time to the closest public general hospital travelling by foot.

As a result of the lack of destinations available within Distrito Tec and in most surrounding areas, eight out of eleven AGEBs of the Distrito Tec's polygon require over a $31 \mathrm{~min}$ travel time to reach the closest destination. From the three AGEBs left, a travel time between 26 and $30 \mathrm{~min}$ is needed to reach the closest public general hospital. These results highlight that the location of hospitals follows metropolitan and regional planning processes, where access at the local scale is not relevant. Additionally, as seen in Figure 16, most of the hospitals tend to cluster. This has to do with the complementarity that one can give to others. A consequence of these localisation patterns is that travel distances from all neighbourhoods that do not have a nearby hospital are considerably high and demand motorised transport modes.

From the previous results, it can be said that Distrito Tec Area is far from becoming a 15 minutes city, if people travel only by foot.

Figure 17 shows the average travel time by AGEB to the closest public general hospital travelling by bike. In comparison to Figure 16, the travel times, both for Distrito Tec and the surrounding areas, drastically decrease. Nonetheless, many AGEBs still are beyond the 15 min parameter. In the Distrito Tec Area, six AGEBs require a 6-10 min travel time, three an 11-15 min travel time and two a 16-20 min travel time.

As nine out of eleven AGEBs meet the parameters to access a public hospital in under 15 min of travel time, the Distrito Tec Area could be considered a 15 minutes city. 
Here, it becomes evident that transport modes dramatically influence access levels and that the location and number of destinations are not the only relevant factors in terms of accessibility.

There are two important lessons from the previous results. The first has to do with the importance that infrastructure at different scales has. One possible solution to improve the access to public general hospitals would be to increase the number of small clinics or medical centres throughout the city. By doing this, people could solve most of their basic health issues at local destinations and travel to large hospitals only when they have complications. The second lesson is that if public general hospitals need to have a metropolitan and regional scale and cluster in specific areas, they need to ensure highquality transit connections. Building roads for cars is not the solution.

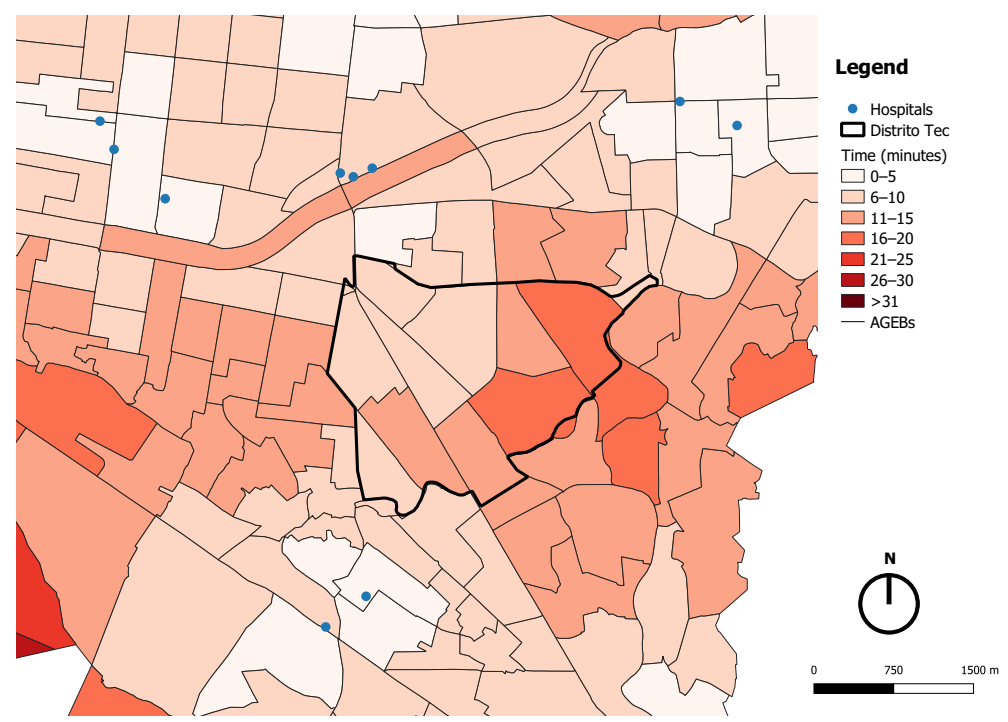

Figure 17. Average time to the closest public general hospital travelling by bicycle.

As $44 \%$ of the daily trips from the MMZ are travel to work, employment is the driving force of mobility. Thus, creating employment opportunities for the population at the local level is key to reducing the population's travel distances and times. By this, negative effects from traffic, such as accidents, pollution and low quality of life, would decrease.

It is important to mention that employment exists in a vast variety of ways. For example, there are many small- to middle-sized economic activities (such as grocery shops or dry cleaners) that are located throughout the entire Metropolitan Area; however, each one of them employs a relatively low number of persons (less than 50). In contrast, large economic activities tend to be less common but employ a larger amount of people $(\geq 51)$. These activities in the MMZ are usually industries (most located in suburban areas) and company headquarters or offices (most located in central areas).

As seen before, at the metropolitan level, the main employment centres (activities that employ $\geq 51$ persons) are located in central areas of the city. As Distrito Tec is considered a privileged location in terms of centrality, it is expected that the number of main economic activities available at the local level will be high.

Figure 18 presents the number of economic activities that employ $\geq 51$ persons (main employment centres) that can be reached from each AGEB within a 15 min travel time by foot. Clearly, most of the main employment centres are located on the two main avenues of Distrito Tec: Av. Eugenio Garza Sada and Av. Revolución.

Even though there is a high number of economic activities, the access levels are relatively low. The 11 AGEBs that compose the Distrito Tec Area are in the same access class of 6-17 destinations within a $15 \mathrm{~min}$ travel time by foot. From the surrounding areas, the northeast, east, southeast southwest, and west have very low access levels, all in the class of 0-6 destinations. This has to do with the low number of economic activities located 
in these areas. Once again, the population living in those areas has to travel to other parts of the city to work, causing traffic, as well as other negative effects.

People highly value the possibility to walk to their job; therefore, it is important to decentralise economic activities and create social housing in central areas that permit the local population to easily access their jobs. Figure 19 shows the number of economic activities that employ $\geq 51$ persons that can be reached by AGEB using a bicycle. As soon as one looks at the map, it is evident that the access levels from the entire area drastically increase. Ten out of eleven AGEBs of the Distrito Tec Area can reach $\geq 105$ destinations and the remaining one 95-105. The surrounding areas also present very high access levels, excluding the east. The eastern area is mainly residential with a gated community urban structure. It is also physically separated from the rest of the city by the river, with a small number of bridges that allow crossing to it. These two factors generate longer-distance trips to access job opportunities, which also results in longer travel times and motorised vehicle dependence.

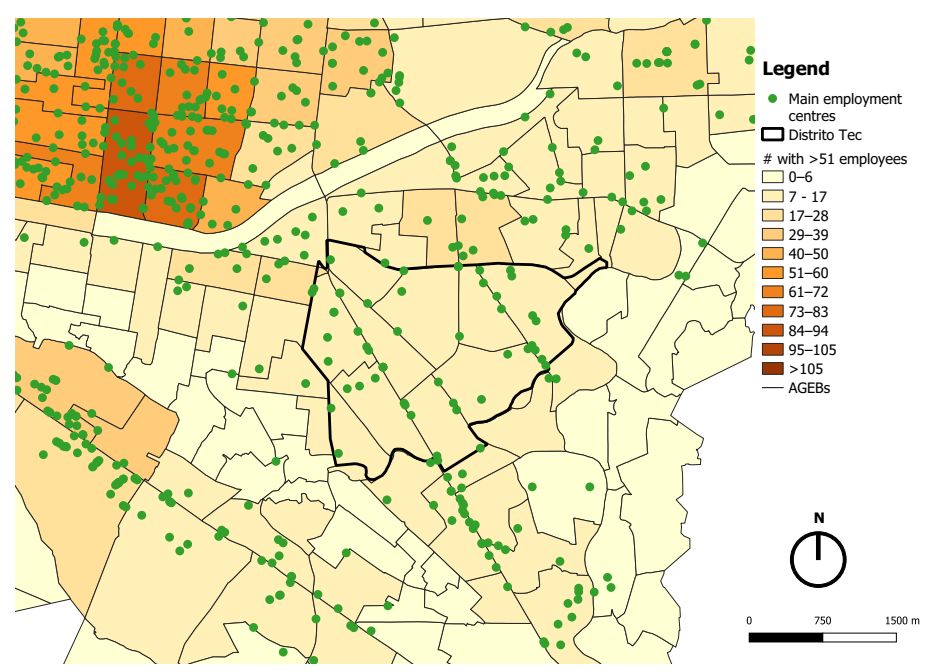

Figure 18. Number of main employment centres reachable within $15 \mathrm{~min}$ travelling by foot.

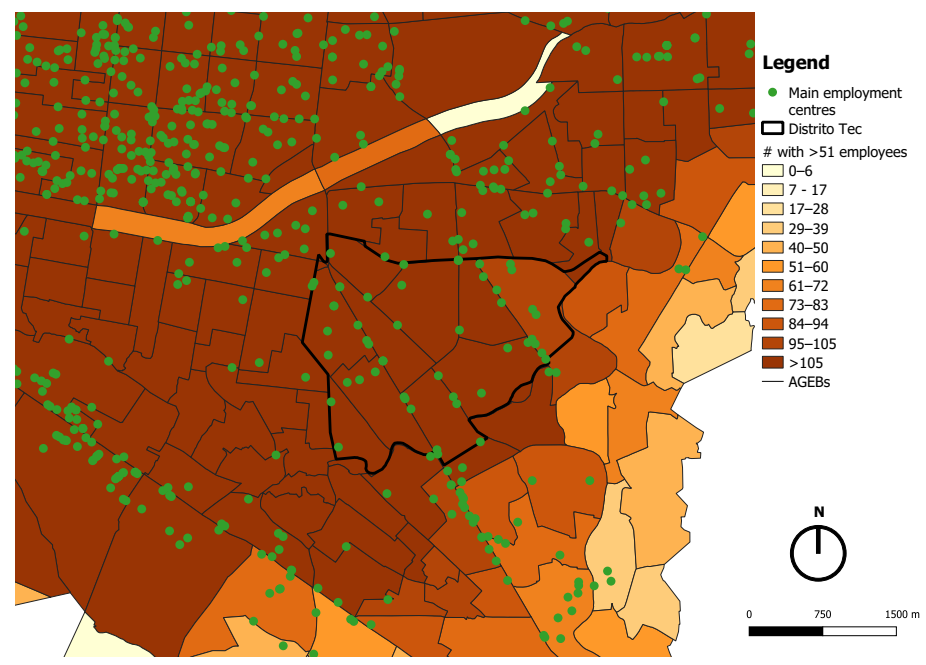

Figure 19. Number of main employment centres reachable within $15 \mathrm{~min}$ travelling by bicycle.

From the results presented in Figures 18 and 19, it can be said that in terms of access to main employment centres, the Distrito Tec Area can be considered a 15 minutes city. Nonetheless, additional information should be gathered to understand the specific type of economic activities located in the area and if the local population has the qualification, interests, and requirements to take those jobs. 
Figure 20 presents the number of supermarkets that can be reached by foot within a travel time of a maximum of $15 \mathrm{~min}$. There are five supermarkets within the Distrito Tec polygon; in the surrounding areas to the west and northeast, there is a high density. In contrast, to the east and southwest, there are no destinations available. To the south, the density is low with all supermarkets concentrating on Eugenio Garza Sada Avenue. The location of supermarkets has negative effects on the mobility of the Distrito Tec Area, as the population living in the eastern neighbourhoods has to travel to or through Distrito Tec to access a supermarket.

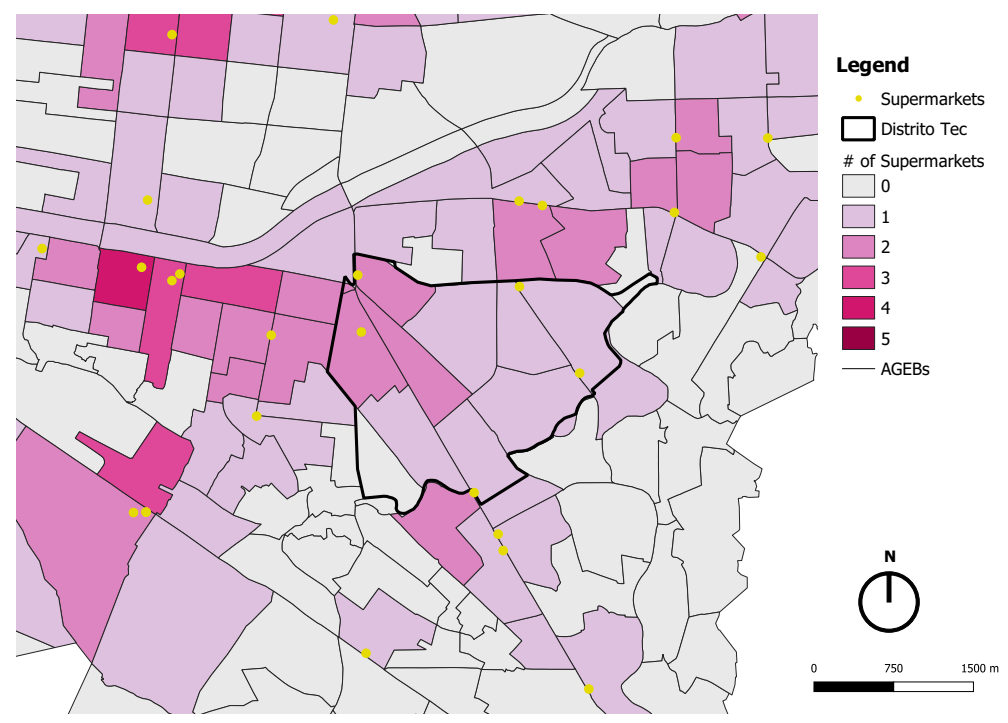

Figure 20. Number of supermarkets reachable within $15 \mathrm{~min}$ of travel by foot.

From the 11 AGEBs that conform the Distrito Tec Area, 2 cannot access a single supermarket, 6 can access 1 destination, and 3 can access 2 destinations. On that account, most of the AGEBs meet the parameters of the 15 minutes city using foot as the travel mode.

Figure 21 shows the number of supermarkets that can be reached by AGEB within a travel time of $15 \mathrm{~min}$ using a bicycle. Immediately, one can appreciate that the number of destinations becomes very high for pretty much the entire area, which is related to the fact that cycling speed is three-times higher than walking.

By bike, all of the AGEBs within Distrito Tec show high accessibility levels, only one AGEB being in the 31-50 destinations class, one AGEB in the 51-69 class, five AGEBs in the 70-93 class, and three AGEBs in the 94-195 class. Such results demonstrate that the Distrito Tec Area comfortably meets the parameters to be considered a 15 minutes city in terms of access to commercial activities (supermarkets). Additionally, the evidence collected is key to understanding the massive potential that cycling has in the city in terms of accessibility. By using this transport mode, the local population can drastically increase their access to commercial activities without relying on motorised vehicles. Once again, this should promote local authorities to create adequate conditions to make cycling safe and comfortable for the local population.

All the previous variables serve as a preliminary approach to understanding to what extent Distrito Tec is ready to become a 15 minutes city in terms of its road network and its destinations' availability. Nevertheless, as mentioned repeatedly, further variables and information have to be taken into consideration to provide a much more accurate analysis of the accessibility and the population's needs in the local area.

The results presented highlight the importance of thinking locally and not just at a metropolitan or regional scale when infrastructure and urban equipment are planned. They also demonstrate that micromobility, especially via bicycles, has a massive potential to increase local accessibility without, necessarily, having to increase the number of amenities in a given area. 


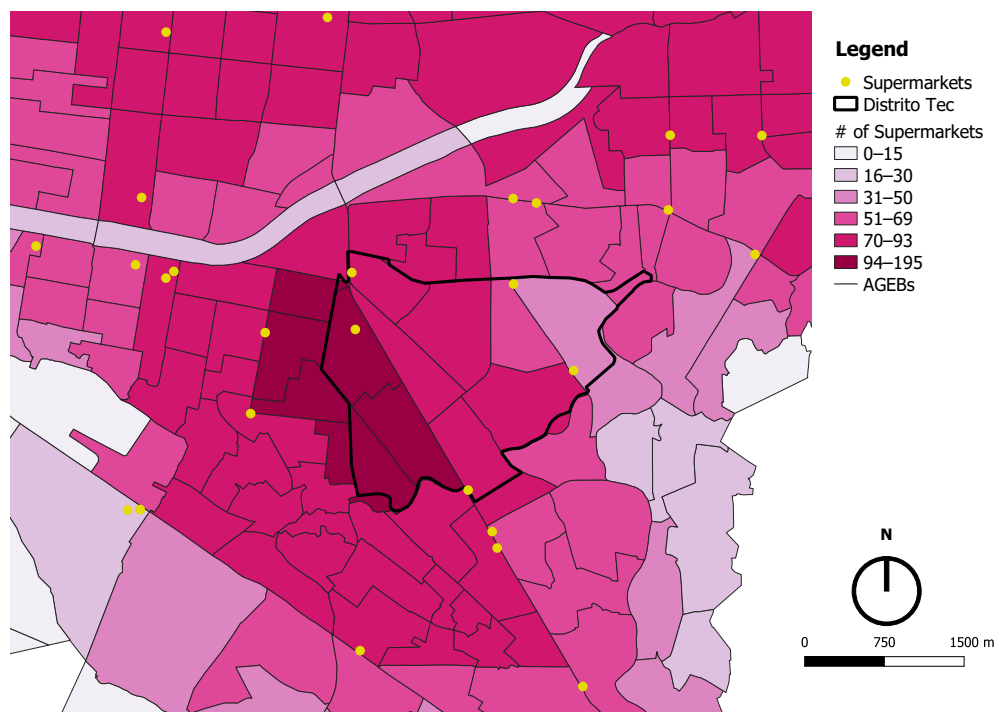

Figure 21. Number of supermarkets reachable within $15 \mathrm{~min}$ of travel by bicycle.

\section{Discussion}

The previous section illustrates that the urban planning processes, as well as the social, political, economic, and environmental factors that have structured the MMZ have failed to fulfil the accessibility conditions that the population requires. Hence, it becomes clear that a change of approach in planning is needed, where high-capacity transit and car-oriented mobility paradigms need to be left behind to adopt an accessibility-based process.

In order to move away from motorised vehicle dependence, not just mobility has to be restructured, but also the land use mix throughout entire cities. The localisation of opportunities in the city dictates the mobility patterns of the population; therefore, if cities want to concentrate on moving people rather than vehicles and creating access instead of traffic, a systemic change to the urban structure is required.

The previous results demonstrated that accessibility can provide extremely disaggregated data based on specific variables. This information is useful for having a starting point for planning processes by identifying priority areas in which to intervene and improve. Nevertheless, additional variables, especially concerning qualitative data (entitlement rights, a specific level of hospital attention, etc.) and social preference, have to be taken into account to obtain a more close-to-reality accessibility model.

After assessing and analysing the accessibility levels of the MMZ and of the Distrito Tec Area, the following recommendations regarding planning processes can be made:

1. Rethink the planning of the city starting at the local level. The results demonstrate that the MMZ is extremely heterogeneous and that not all of the population of urban areas has the same needs. Hence, before thinking about what interventions at a large scale have to be made, it is important to understand what is happening at the microlevel. To do so, speaking to citizens and opening citizen participation spaces are crucial to extract relevant information about what are the most important needs. If this process is replicated throughout the entire city, many of the metropolitan issues will be solved without having to perform metropolitan interventions. This is a win-win procedure, as the authorities spend less of their budgets and do so more wisely and local people obtain tailor-made solutions to their problems;

2. Embrace land use mixture. People need more than their house to carry out their daily lives. Therefore, each neighbourhood should have enough land use mixture to allow the local population to access commercial activities, recreation, education, employment, and health. If people can find all these opportunities in the vicinity of their household, mobility and all its negative effects would dramatically reduce. Furthermore, the short distances that people would require to travel would encourage the use of sustainable transport modes such as walking or cycling. The authorities 
have a key role in influencing the structure of the city through building permits. Thus, they should not provide any permits to create residential areas unless they ensure that the needed land use mix will be available for the local population to address their daily needs;

3. Promote the use of bicycles and other micromobility vehicles. The results demonstrate that using a bike drastically increases the number of destinations that a person can reach in a given time. Therefore, the improvements that have to be made in terms of mobility and transport networks in the MMZ and at the local level should concentrate on increasing the quality and coverage of public transport for metropolitan journeys and creating open streets with safe and comfortable cycling lanes for short and local trips. By doing so, the number of destinations (opportunities) does not necessarily have to be increased, but only the ease of reaching them. If the MMZ wants to reduce the extreme use of motorised vehicles, the first step to take is to reduce the public space designated to them by creating a safe built environment for other transport users;

4. Accessibility is a social and gender policy. Usually, the groups with the lowest incomes live in areas of the city where accessibility levels are low and marginalisation levels are high; this is not an exception for the MMZ. Therefore, increasing accessibility in such areas will bring massive benefits to such populations as their transportation expenditures (for the specific case of women, this is known as the "Pink Tax") will decrease, as well as their travel distances and times, hence improving their quality of life and sense of belonging to their local community. Additionally, women in Mexican cities usually have more complex travel patterns than men, as they tend to visit many different destinations in one day (trip-chaining), carry heavy things, and accompany other persons (mobility of care) in their trips [23]. Consequently, making all these destinations easier and less expensive to access will bring important improvements to the travel behaviours and patterns of women. Finally, women argue that they usually feel unsafe when using public transport [23]; thus, using bikes and walking as their main transport modes will make them feel safer in their daily trips. In addition, further research should be conducted to assess the changing needs of an ageing society and accessible mobility in MMZ;

5. Decentralise the city. As in many other cities in the world, most of the main employment centres of the city are located in central areas. This localisation pattern results in a phenomenon where, during the morning, the origin of most trips to go to work is from suburban areas, and the destination is the centre of the city. In the afternoon, most people travel back home, and the mobility pattern is inverted, starting in the centre and ending in suburban areas. Such a way of structuring the city creates traffic, as well as extremely long average distances and travel times, which result in high economic, social, and environmental costs. Hence, it is important to apply planning processes or economic activities (especially commerce and services) that encourage the localisation of such activities in different parts of the city, creating subcentres and reducing the need for metropolitan mobility.;

6. Increase the density of the city. With only 698 people per square kilometre, the MMZ is not a dense city. Large sprawling cities with low densities go against accessibility, as there is not enough critical mass (demand) to implement some opportunities throughout the entire city. This generates a dependency on middle to large-distance motorised travel. Considering the nature of the MMZ, it is recommended that the city no longer sprawl. To do so, it has to generate all-income-level vertical housing in central areas. The authorities play a key role in doing so by putting in action economic incentives for developers (such as tax waivers or reductions) to build social vertical housing in central areas and by eradicating any permits to develop large monofunctional suburban residential gated communities. This is an ambitious plan for a city like the MMZ, as it has historically grown horizontally and with most of its population preferring single-family housing schemes rather than apartments. 
Nevertheless, the transformation of its urban structure to a denser area will bring massive social, economic, and environmental benefits to the local population in the short, middle, and long term;

7. Downsize urban infrastructure and equipment. It has been demonstrated that highcapacity and large-scale destinations such as public general hospitals or shopping centres attract many persons who live in other districts. Therefore, having a larger number of small-scale opportunities dispersed along the city would allow locals to access their daily needs in their neighbourhood. This would drastically reduce middle to long distance mobility, as well as the use of motorised vehicles. It is important to mention that certain destinations, such as specialised hospitals, will still have a metropolitan radius of influence. For these kinds of opportunities, sustainable and diverse transport alternatives have to be guaranteed;

8. Use of technology. One of the major lessons that the COVID-19 pandemic has left is the massive potential that technology has to reshape education, commerce, and employment. This can generate important changes in the urban realm. By encouraging the use of technology in schools, commerce, and employment centres (e-learning, e-commerce, and home offices), mobility can drastically reduce the need to go to a specific location every day. Lowering the number of travelling people reduces the overloading of public transport, as well as the traffic levels, bringing important social, economic and environmental benefits. Additionally, spaces that are no longer needed, such as some office buildings, can be reconverted (taking advantage of their usual central location) to other uses such as commerce, housing, or schools. Finally, it must be said that using technology brings considerable economic benefits to employers, the government, and society, as mobility is expensive for all.

As part of the further research that can be performed to complement the current investigation, it will be important to incorporate more socio-economic and demographic factors that help provide a more accurate understanding of the qualitative differences that also affect the degree of accessibility in a given city. By doing so, the relationship between marginalisation levels and other social variables such as income, age, or gender with the level of accessibility will become clearer, providing useful data for developing public policies and urban interventions. Considering new accessibility measures to other destinations as green areas, universities and minor employment centres and more local commerce such as pharmacies or small shops can provide very useful data of the local level configuration of the city in different areas. These additional measures can also help to develop specific public policies based on the topic being analysed; for example, accessibility to green areas.

Even though the concept of the 15 minutes city focuses on transport modes such as walking and cycling, it would be relevant to run the accessibility measures using other transport modes, especially public transport and private vehicles. For this to be done, it is important to generate the necessary data, such as GTFS for public transport and a database that provides the average speed for private vehicles per road per time of the day.

The previous paragraph encloses a compilation of ideas that could complement and expand the current scope of work. It is important to consider that multiple variables play a dynamic role in the analysis of accessibility in a city, and by understanding this, it becomes clear that the possibilities to analyse accessibility from different perspectives are vast.

\section{Conclusions}

The urban realm is in constant and rapid transformation. Every day, new social, economic, and environmental needs arise, and cities have to evolve to satisfactorily overcome the challenges. However, this is not an easy task, as the number of variables and elements that conform the great system known as the city are uncountable.

Hence, dealing with complexity has become one of the biggest challenges for policymakers and urban planners. The fast rate of change in cities demands tailor-made solutions for each specific context, in very short periods of time, that respond to short-, medium- and 
long-range time frames. Traditional planning has failed to do so, and this has to do, to a certain extent, with the approach taken. Humans like to think that a new invention can be the answer to all our problems, and the car was considered so. During the Twentieth Century, the car-dominated all urban planning processes, as it was seen as the ultimate alternative for mobilising goods and people within and around urban areas. Nevertheless, car-oriented planning was soon demonstrated to be unsustainable due to the extremely negative social and environmental effects that it has.

Taking more holistic, people-centric, and humble approaches to plan can be a more effective and equitable way to deal with complexity. Major urban planning and infrastructure interventions, on the other hand, in the urban realm take a long time to mature, and they can only be assessed after completion. Therefore, iterating planning processes can provide useful information about the rate of success of a given intervention to deal with a specific issue and allow the possibility to adjust the solution before being fully implemented. To do so, a huge amount of data has to be gathered and processed. On that account, technology plays a key role in urban planning, by providing high-quality open data, such as those collected from INEGI, and software, such as UrMoAC, with which urban planners can model at a high level of accuracy the state of a city. This allows a clear understanding of the issues of different parts of a city, permitting the elaboration of a hierarchy-based intervention.

Additionally, cities have to have a comparable and, ideally, standardised methodology to assess urban accessibility. By doing so, benchmarking, as well as the evaluation of public policies and urban interventions can be directly compared between cities of the same country, region, or even at a worldwide scale. This allows planners to argue to what extent a change is being made and at what rate. The current research project adds to that by using a transferable approach that can be replicated in different cities, making comparison of the results possible.

The results from the current research project demonstrate that taking an approach to urban planning based on accessibility provides many benefits in terms of sustainable planning. Accessibility measures permit obtaining highly disaggregated data of the performance of every part of the city regarding a specific variable, highlighting the areas with higher intervention needs and providing results that contrast how different transport modes perform for accessing a specific destination. Thus, using accessibility as the pillar of urban planning will allow cities into transform to more inclusive, environmentally friendly, and comfortable places to live.

Most cities in the world are still far from becoming 15 minutes cities, especially when whole metropolitan areas are considered, and the MMZ is not an exception. However, having this travel time frame as an objective should encourage policymakers, citizens and the private sector to transform cities from the local to the metropolitan level. It is also important to understand that in order to truly transform cities into better living environments, not only central areas need intervention, but the whole urban area. Everyone plays a key role in such a transformation, as it is necessary to agree that the current state of cities is going against sustainability and that an urgent urban, social, economic, political and environmental transformation is needed.

Author Contributions: Conceptualisation, J.d.-J.L.-S. and R.A.R.-M.; methodology, A.L.G.-B., J.N.-B. and M.A.R.-M.; software, A.L.G.-B., J.N.-B., M.A.R.-M. and D.K.; validation, J.N.-B. and D.K.; formal analysis, A.L.G.-B., J.N.-B. and M.A.R.-M.; investigation, A.L.G.-B., J.N.-B. and M.A.R.-M.; resources, R.A.R.-M. and J.d.-J.L.-S.; data curation, A.L.G.-B., J.N.-B. and M.A.R.-M.; writing-original draft preparation, A.L.G.-B., J.N.-B. and M.A.R.-M.; writing-review and editing, D.K., B.L.P.-H. and J.d.J.L.-S.; visualisation, A.L.G.-B., J.N.-B., M.A.R.-M. and J.d.-J.L.-S.; supervision, R.A.R.-M., B.L.P.-H., D.K. and J.d.-J.L.-S.; project administration, M.A.R.-M., R.A.R.-M. and J.d.-J.L.-S.; funding acquisition, R.A.R.-M. and J.d.-J.L.-S. All authors read and agreed to the published version of the manuscript.

Funding: This research received funding by the CampusCity Initiative of the Tecnologico de Monterrey. CampusCity Initiative is funded by Fundación FEMSA. Fundación FEMSA had no role in study design, data collection and analysis, decision to publish, or preparation of the manuscript. 
Institutional Review Board Statement: Not applicable.

Informed Consent Statement: Not applicable.

Data Availability Statement: The data used in this study were obtained from public databases and can be found in Table 1 .

Acknowledgments: Special thanks to the Deutsches Zentrum für Luft-Raumfahrt (DLR) for making UrMoAC an open-source software and sharing relevant information about its use with our research team. The authors would also like to thank the Distrito Tec team, from the Instituto Tecnológico de Monterrey, for giving relevant information and feedback throughout the development of the entire project. We acknowledge as well the support of the California-Global Energy, Water \& Infrastructure Innovation Initiative at Stanford University and the expedient proofreading by Josh Dimon

Conflicts of Interest: The authors declare no conflict of interest.The founders had no role in the design of the study; in the collection, analyses, or interpretation of data; in the writing of the manuscript; nor in the decision to publish the results.

\section{References}

1. Nations, U. Cities and Polution. Available online: https://www.un.org/en/climatechange/climate-solutions/cities-pollution\#: $\sim$ :text=According $\% 20$ to $\% 20$ UN\%20Habitat $\% 2$ C $\%$ cities, cent $\% 20$ of $\% 20$ the $\% 20$ Earth $\% 27 \mathrm{~s} \% 20$ surface (accessed on $28 \mathrm{May} 2021$ ).

2. Leo, A.; Morillón, D.; Silva, R. Review and analisys of urban mobility strategies in Mexico. Case Stud. Transp. Policy 2017, 5, 299-305. [CrossRef]

3. Chavez-Rodriguez, L.; Lomas, R.T.; Curry, L. Environmental justice at the intersection: Exclusion patterns in urban mobility narratives and decision making in Monterrey, Mexico. DIE ERDE J. Geogr. Soc. Berl. 2020, 151, 116-128. [CrossRef]

4. Montalvo-Urquizo, J.; Villarreal-Marroquín, M.G.; Hernández-Castillo, J.J.; Hernández-González, H.E. MWTP: Monterrey Weather, Traffic and Pollution Database for Geospatial Analysis. arXiv 2017, arXiv:1703.04526.

5. Sisto, N.P.; Ramírez, A.I.; Aguilar-Barajas, I.; Magaña-Rueda, V. Climate threats, water supply vulnerability and the risk of a water crisis in the Monterrey Metropolitan Area (Northeastern Mexico). Phys. Chem. Earth 2016, 91, 2-9. [CrossRef]

6. de Nuevo León, G. Programa Integral de Movilidad Urbana Sustentable (PIMUS-ZMM). 2010. Available online: https: //www.nl.gob.mx/publicaciones/documento-ejecutivo-pimus (accessed on 19 March 2021).

7. Hancke, G.P.; de Silva, B.C.; Hancke, G.P. The role of advanced sensing in smart cities. Sensors 2013, 13, 393-425. [CrossRef] [PubMed]

8. Tec, D. Distrito Tec. 2021. Available online: http://distritotec.itesm.mx/categorias/colonias/ (accessed on 19 March 2021).

9. Rezende, D.A.; Bustani, C.E.G. The urban districts and tourist improvement in the Strategic Digital City: The DistritoTec in Monterrey, Mexico. TURyDES Rev. Tur. Desarro. Local 2018, 11, unpaginated.

10. Krajzewicz, D.; Heinrichs, D.; Cyganski, R. Intermodal Contour Accessibility Measures Computation Using the 'UrMo Accessibility Computer'. Int. J. Adv. Syst. Meas. 2017, 10, 111-123.

11. Mora, H.; Gilart-Iglesias, V.; Pérez-Del Hoyo, R.; Andújar-Montoya, M.D. A comprehensive system for monitoring urban accessibility in smart cities. Sensors 2017, 17, 1834. [CrossRef] [PubMed]

12. Geurs, K.; Ritsema van Eck, J.R. Accessibility Measures: Review and Applications. Evaluation of Accessibility Impacts of Land-Use Transportation Scenarios, and Related Social and Economic Impact; Technical Report 90715; Netherlands Environmental Assessment Agency: The Hague, The Netherlands, 2001. Available online: https://www.pbl.nl/en/publications / Accessibility_measures_ _review_and_applications (accessed on 19 March 2021).

13. Moreno, C.; Allam, Z.; Chabaud, D.; Gall, C.; Pratlong, F. Introducing the "15-minutes City": Sustainability, Resilience and Place Identity in Future Post-Pandemic Cities. Smart Cities 2021, 4, 6. [CrossRef]

14. Oswald Beiler, M.R.; Phillips, B. Prioritizing Pedestrian Corridors Using Walkability Performance Metrics and Decision Analysis. J. Urban Plan. Dev. 2016, 142, 04015009. [CrossRef]

15. Krajzewicz, D.; Nieland, S.; Balzaretti, J.; Heinrichs, D. Assessing Sustainable Development Goals: A Transferable Approach Using Contour Accessibility Measures at the Example of Berlin and Mexico City. In Proceedings of the MOVICI-MOYCOT 2018: Joint Conference for Urban Mobility in the Smart City, Medellin, Colombia, 18-20 April 2018, pp. 1-7. doi:10.1049/ic.2018.0010 [CrossRef]

16. Park, S.; Nielsen, A.; Bailey, R.T.; Trolle, D.; Bieger, K. A QGIS-based graphical user interface for application and evaluation of SWAT-MODFLOW models. Environ. Model. Softw. 2019, 111, 493-497. [CrossRef]

17. Kwan, M.P. Space-time and integral measures of individual accessibility: A comparative analysis using a point-based framework. Geogr. Anal. 1998, 30, 191-216. [CrossRef]

18. López-Alonso, M. Growth with Inequality: Living Standards in Mexico, 1850-1950. J. Lat. Am. Stud. 2007, 39, 81-105. [CrossRef]

19. CONAPO. Anexo C Metodología de Estimación del Índice de Marginación Urbana. 2010. Available online: http:/ / www.conapo. gob.mx/work/models/CONAPO/Resource/862/4/images/06_C_AGEB.pdf (accessed on 28 May 2021). 
20. CONAPO. Datos Abiertos del Índice de Marginación. Available online: http://www.conapo.gob.mx/es/CONAPO/Datos_ Abiertos_del_Indice_de_Marginacion/(accessed on 28 May 2021).

21. Saroha, J. Types and Significance of Population Pyramids. World Wide J. Multidiscip. Res. Dev. 2018, 4, 59-69.

22. Bai, X.; Nagendra, H.; Shi, P.; Liu, H. Cities: Build networks and share plans to emerge stronger from COVID-19. Nature 2020, 584, 517-520. [CrossRef] [PubMed]

23. Soto-Villagrán, P. Análisis de la Movilidad, Accesibilidad y Seguridad de las Mujeres en tres Centros de Transferencia Modal (CETRAM) de la Ciudad de México; Technical Report IDB-TN-1780; Banco Interamericano de Desarrollo: Mexico City, Mexico, 2019. [CrossRef] 